\title{
Economic Analysis of Supply Response of Broad Beans Crop in Egypt
}

\author{
Moataz Eliw iD \\ Department of Agricultural Economics, Faculty of Agriculture, Al-Azhar University, Assiut, Egypt
}

*Correspondence:

(E-mail: moatazeliw@azhar.edu.eg )

Received: $31 / 08 / 2021$

Revised: $\quad 16 / 09 / 2021$

Accepted: 23/09/2021

Published: 23/09/2021

\begin{abstract}
The Broad beans crop in Egypt is considered a major source of food for a great number of the population; in recent years its prices have witnessed a significant increase, despite it being considered an alternative to animal protein, whose prices have also witnessed a huge increase. This research aims to study the supply response of Broad beans crop in Egypt, through studying the production and economic indicators, also identifying the most important variables impact on response of the cultivated area, and estimating the degree of response for most important variables which impact on the response of cultivated area of Broad beans crop in Egypt, besides estimate the annual amount of response to reach the period necessary to achieve a full response.

The results showed that the cultivated area with Broad bean has taken a general and statistically significant decreasing trend, reached 11.14 thousand acres, with an annual decrease rate $7.57 \%$ of the cultivated area average. The results of the supply response function also indicated that there is a logical inverse relationship between each of Broad beans cultivated area (as a dependent variable) and the farm price of lentil, Clover, Chickpeas, Flax and Onion with Egyptian pounds in the previous year (as explanatory variables).
\end{abstract}

Keywords: Supply Response; Nerlove Model; Broad beans 


\title{
تحليل اقتصادى لاستجابة عرض محصول الفول البلدى فى مصر
}

\author{
معتز عليو مصطفى أحمد \\ قسم الاقتصاد الزراعى - كلية الزراعة بأسيوط- جامعة الأزهر \\ moatazeliw@azhar.edu.eg
}

\section{الملخص العربى}

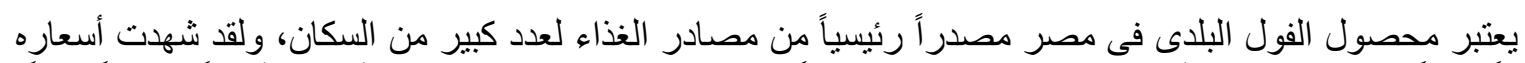

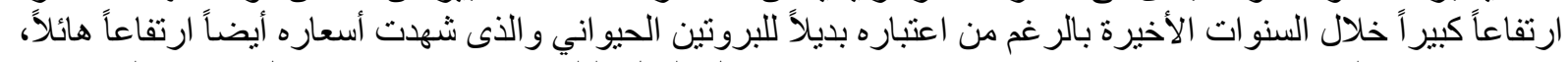

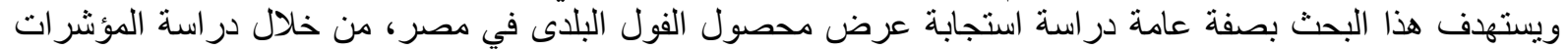

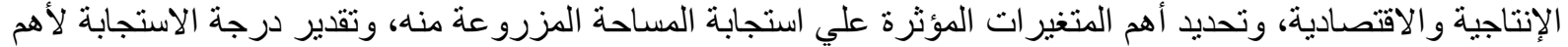

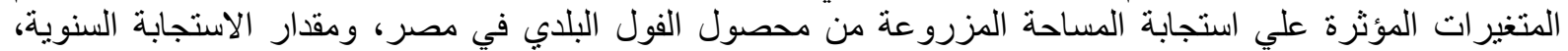

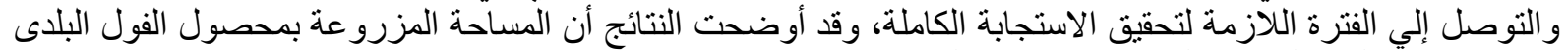

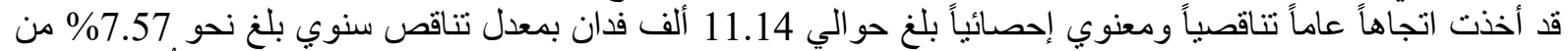

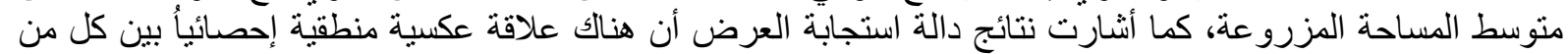

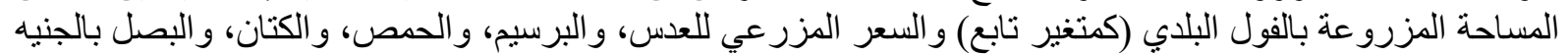

فى العام السابق (كمتغير ات تفسيرية).

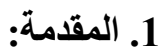

و الاستهلاك و انخفاض نسبة الإكتفاء الذاتي منه، ويعزى ذلك

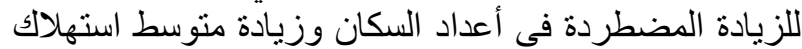

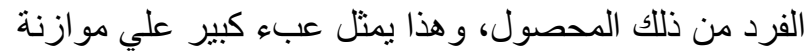

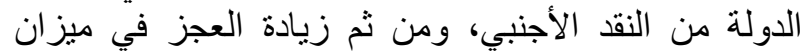

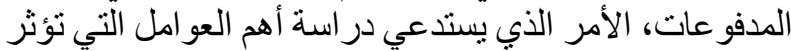

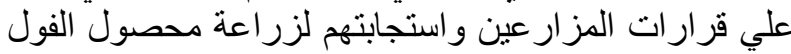
البلدى فى مصر. 3. أهداف البحث:

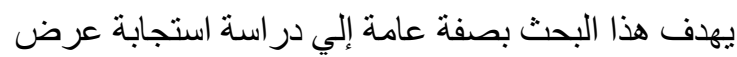

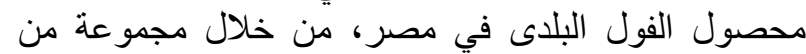
الأهداف الفر عية التالية:

در اسة تطور المحددات الإنتاجية و الاقتصادية لمحصول الفول البلدي في مصر خلال الفترة (2003-2019). تحديد أهم المتغيرات المؤثرة علي استجابة المساحة

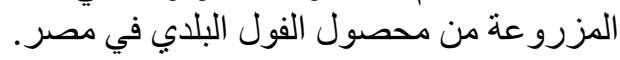
تقدير درجة الاستجابة لأهم المتغيرات المؤثرة علي

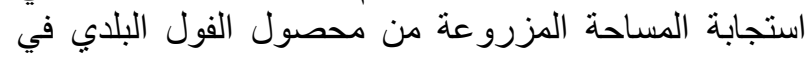

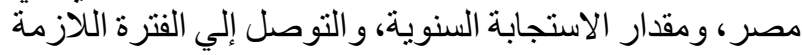
لتحقيق الاستجابة الكاملة.

\section{4. الطريقة البحثية ومصادر البيانات:}

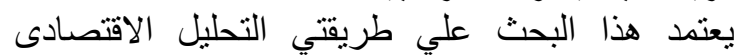

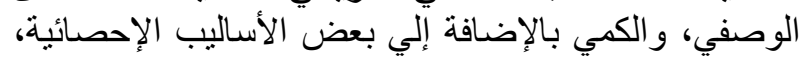

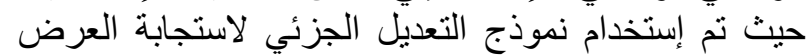
و المعروف بنموذج نيرلوف، وذللك باستخدام أساليب التحليل

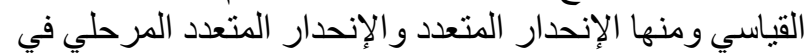

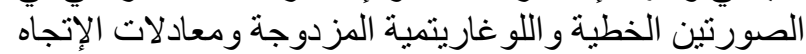

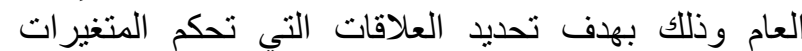
الرئيسية في الدراسة، و القياس الكمي لها.
يعتبر محصول الفول البلدي من أهم المحاصبيل الغذائية

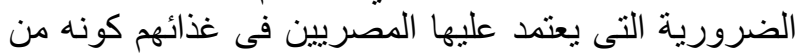

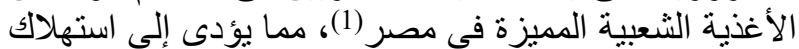

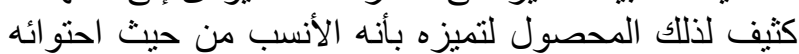
علي النسب المرتفعة من البروتين (3)، التي تصنل إلي نحون التهو

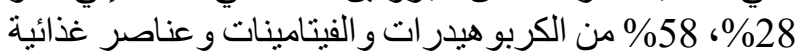

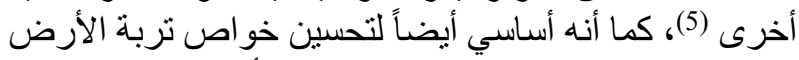

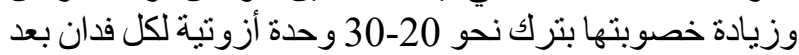

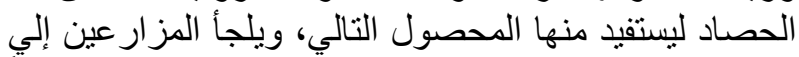

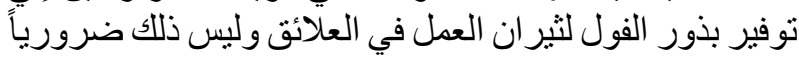

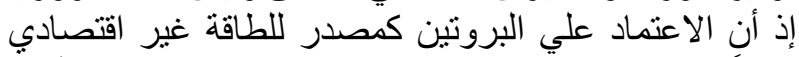

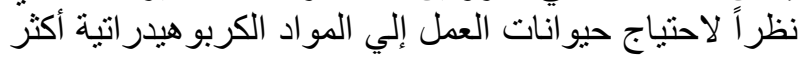

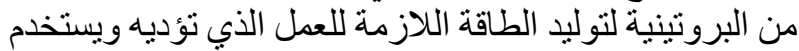
الدريس الناتج من سوق النباتات كغذاء للمو اشتى (4). انخفضت المساحة المزروعة بمحصول الفول البلدى في

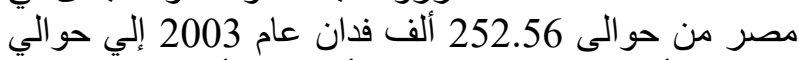

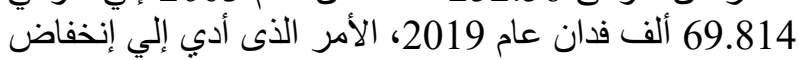

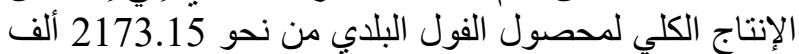

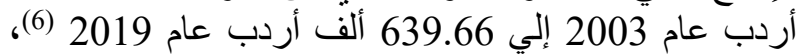
وذلك بسبب عزوف المز ارعين عن زر اعته، لكونه محصول

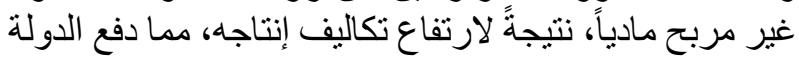
إلى استير اد كميات كبيرة منه تصل إلى 90 \%

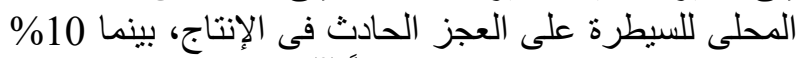
من ذللك المحصول يتم إنتاجه محلياً (2).

2. مشكلة البحث:

تتمثل مشكلة البحث في إنخفاض الإنتاج الكلى من النماض

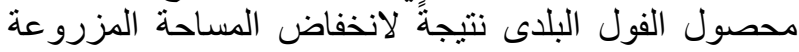

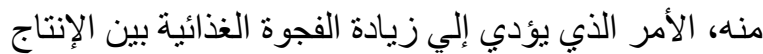


حيث $\lambda$ معامل الاستجابة السنوى (معامل التعديل)، (2 (1/

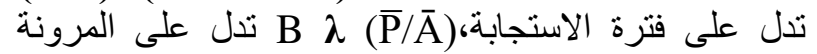

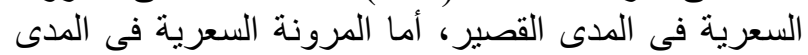

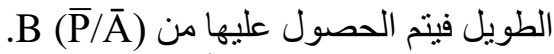

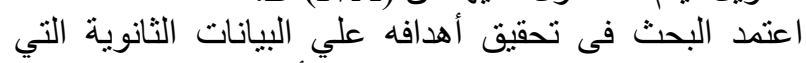

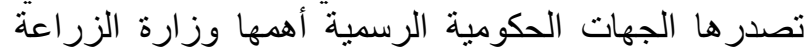
واستصلاح الأراضي، الجهاز المركزي الإسية اللتعبئة العامة الزاتة

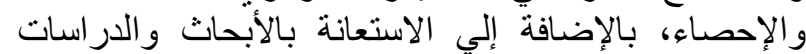

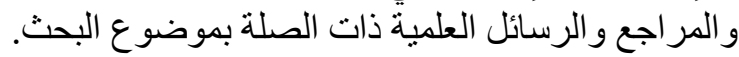

$$
\text { 5. النتائج والمناقشة: }
$$

أولاً: تطور المحددات الإنتاجية والاقتصادية لمحصول الفول البلدي في مصر خلال الفترة (2003-2019):-

توضح بيانات الجدول رقم (2)، المعادلة (3) أن الإنتاج

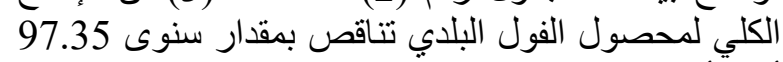

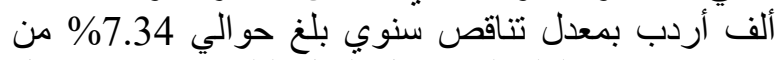

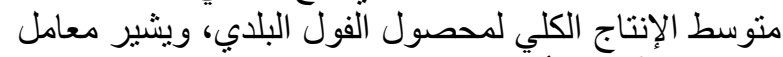

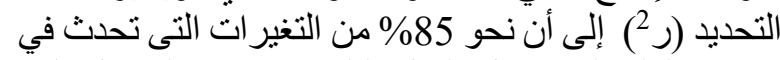

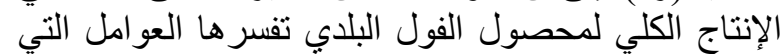

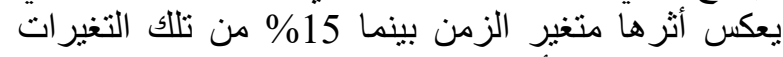
ترجع الى عو امل أخرى غير مقئ مقيسه بالدالة.

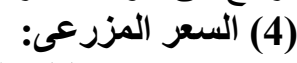

بيتبين من بيانات الجدول رقم (1)، العزين أن متوسط السعر (2003 المزرعى لمحصول الفول البلدي خلانل الفترة الفترة (2003-

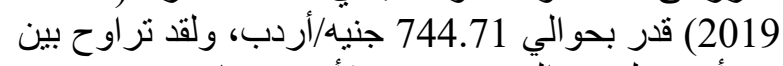

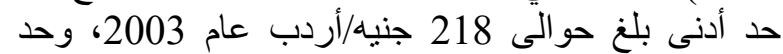

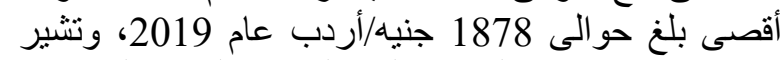

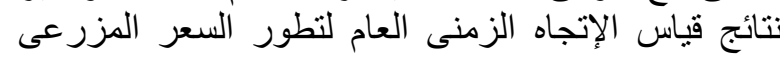

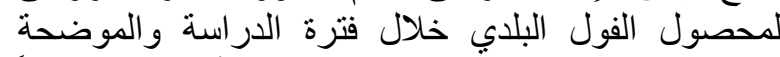
بالجدول رقم (2) المعادلة رقم (4)، إلى أن هنالك إنجاهياً

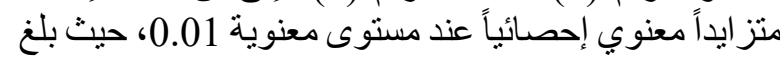

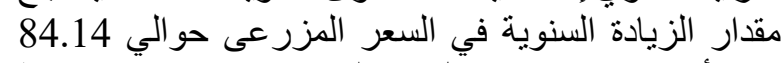

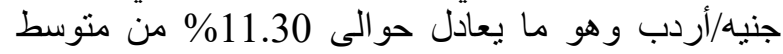
السعر المزرعى لمحصول الفول البلدي خلال تلإلك الفترة

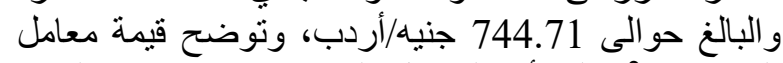

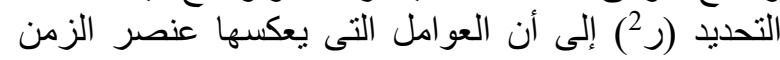

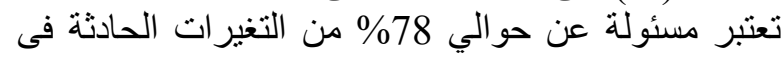

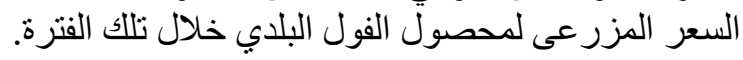

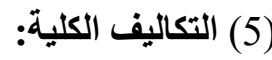

تشير بيانات الجدول السابق رقم (1)، أن منوسط

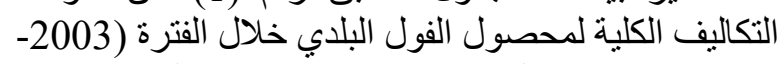

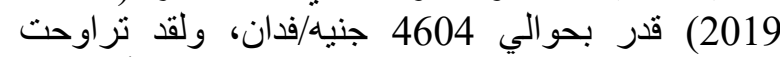

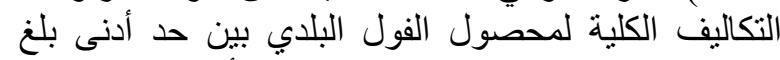

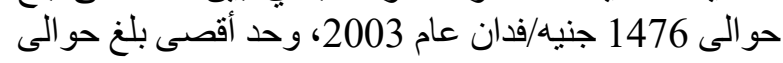
10441 جنيه/فدان عام 2019، ونتير 2003 ونتائج قياس الإتجاه

$$
\begin{array}{r}
\alpha=\hat{\mathrm{B}}_{0} / \lambda . \quad \mathrm{B}=\hat{\mathrm{B}}_{1} / \lambda . \quad \lambda=1-\hat{\mathrm{B}}_{2} . \lambda \quad \mathrm{U}_{\mathrm{t}} \\
=\mathrm{U}^{*}{ }_{\mathrm{t}}
\end{array}
$$

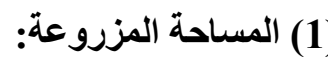

\section{توصيف النموذج (7):}

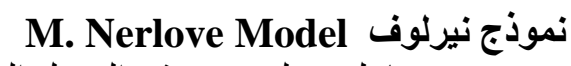

وضع مارك نيرلوف نموذج التعديل الجزئى على أساس

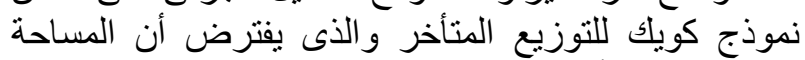

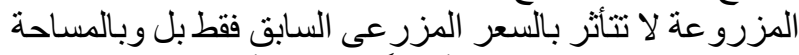

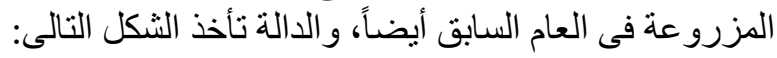
$\mathrm{A}_{\mathrm{it}}=\alpha \lambda+\mathrm{B} \lambda \mathrm{P}_{\mathrm{i}(\mathrm{t}-1)}+(1-\lambda) \mathrm{A}_{\mathrm{i}(\mathrm{t}-1)}+\lambda \mathrm{U}_{\mathrm{t}}$ بينما يأخذ النموذج المقدر الثكل التالى: $\mathrm{A}_{\mathrm{it}}=\hat{\mathrm{B}}_{0}+\hat{\mathrm{B}}_{1} \mathrm{P}_{\mathrm{i}(\mathrm{t}-1)}+\hat{\mathrm{B}}_{2} \mathrm{~A}_{\mathrm{i}(\mathrm{t}-1)}+\mathrm{U}^{*} \mathrm{t}$

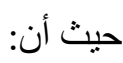

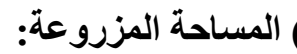

من خلال در اسة البيانات الو اردة بالجدول رقم (1) تبنه

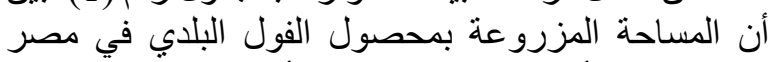

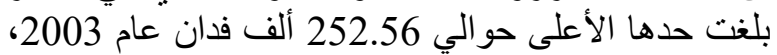
بينما بلغت حدها الأدنى حوالي 69.814 ألف الف فدان عام

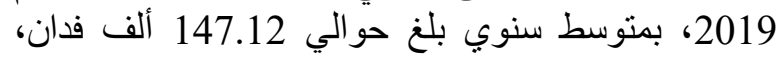
وبتقدير معادلة الإتجاه الزمني العآم للمساحة المزروعة المئ،

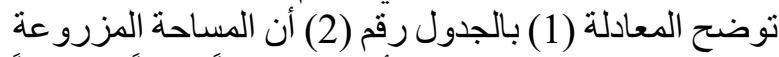

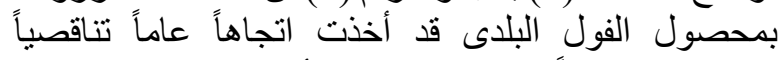

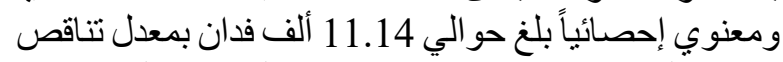

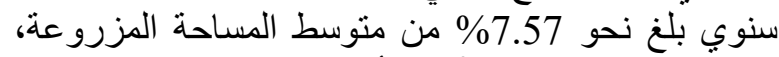

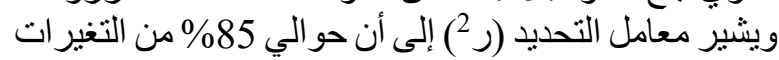

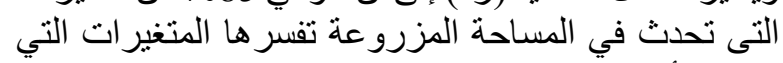

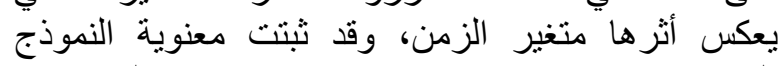

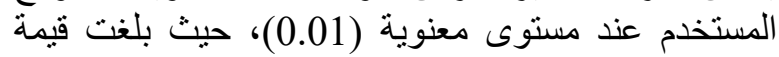
"ف" حوالي 82.95. (2) الإنتاجية الفدانية:

من خلال استعر اض بيانات الجدول رقم (1) تبين أن الإنه

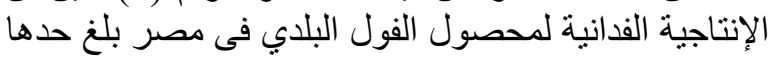

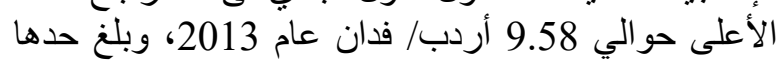

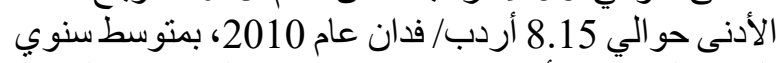

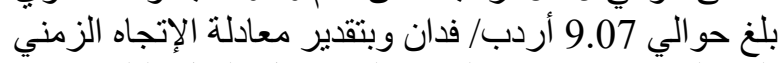

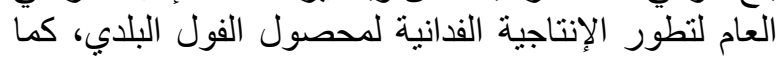

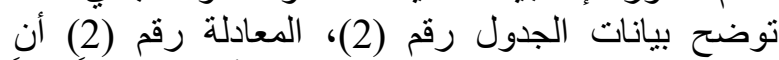
الإنتاجية الفدانية لمحصول الفئات الفول البلدي قد أخذت إتجاهاً عاماً

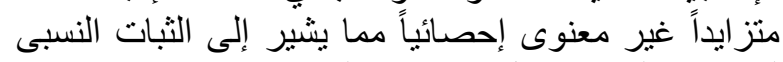
للإنتاجية الفدانية حول متوسطئ الإنها السنوى (3) الإنتاج الكلي:

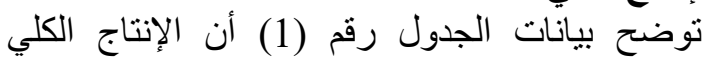
لمحصول الفول البلدي فى مصر خلال الفي الفترة (2003 الإنتاجي

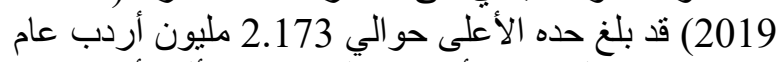
2003، بينما بلغ حده الأدنى حو ألي 639.7 ألف الف أردب أرب عام عام 2019، بمنتوسط سنوي بلغ حو الادي حولي 1.326 مليون أردب، كما أردب 
بدر اسة البيانات الو اردة بالجدول رقم (1) تبين أن نسبة

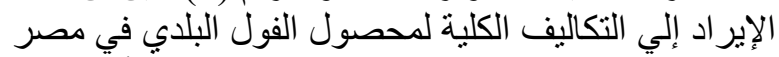

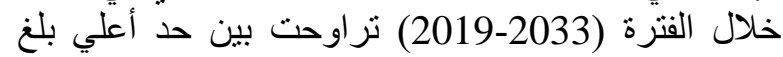

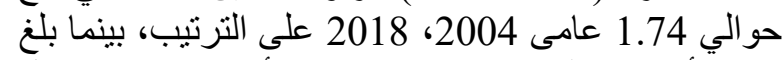

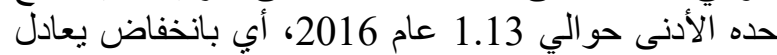

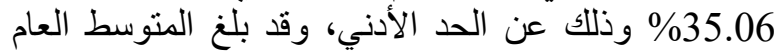
لنسبة الإير اد إلي التكاليف لمحصول الفول اللبلدي خلال تللك الكئ

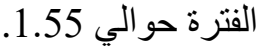
وبتقدير معادلة الإتجاه الزمني لمحصول الفول البلدي

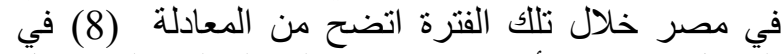
الجدول رقم (2) أن نسبة الإيراد إلي التكاليف لمحصول الفول البلاي قد تناقصت بمقدار سنوي غير معنوي إحصائياً.

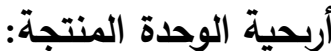

من خلال استعر اض البيانات الو اردة بالجدول رقم

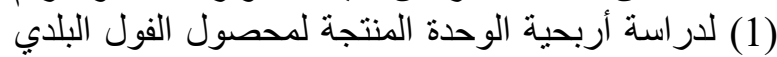

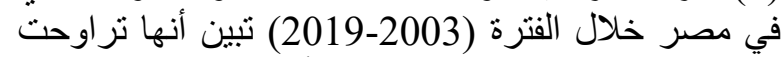

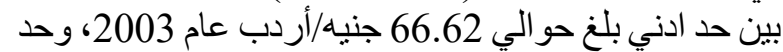

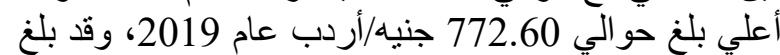

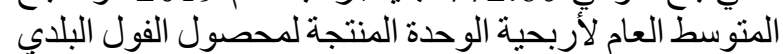

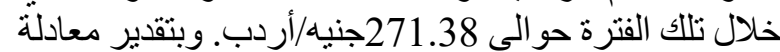

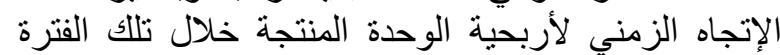

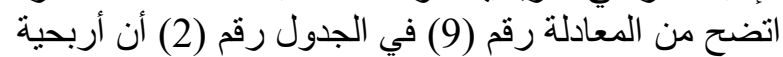

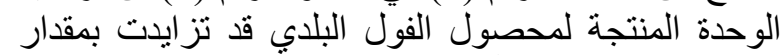

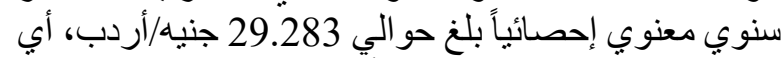

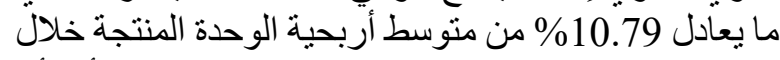

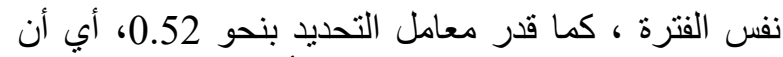

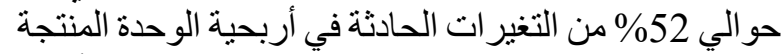

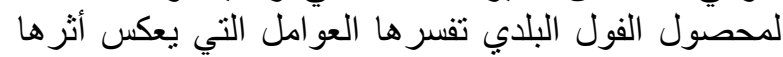

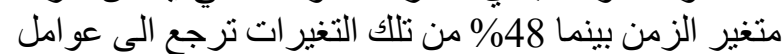
أخرى غير مقيسه بالالة.

$$
\text { (10) عائد الجنيه المستثمر: }
$$

بدر اسة عائد الجنيه المستنمر لمحصول الفول البلدي البلدي في

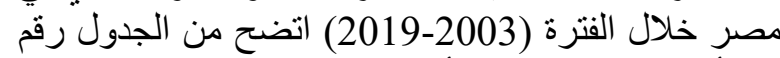

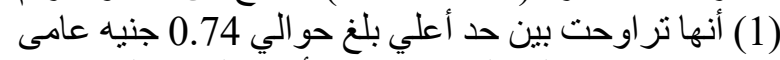

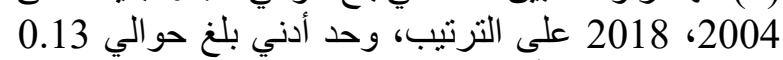

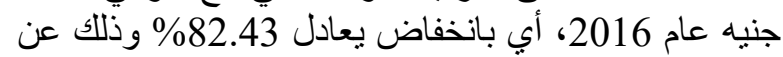
الحد الأدني، وقد بلغ المتوسط العام لعائد الجنيه المستثمر لمحصول ألفول البلدي خلال تللك الفترة حو الي 0.55 جنيه. وبتقدير معادلة الإتجاه الزمني لعائد الجنيه المستثر في لئي

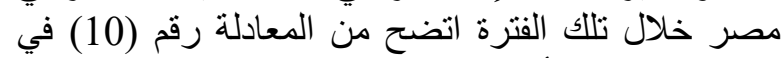

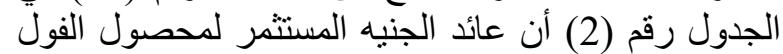
البلدي قد تناقص بمقدار سنوي غير معنوي إحصائياً.
الزمني العام لتكاليف إنتاج محصول الفول البلدي فى مصر

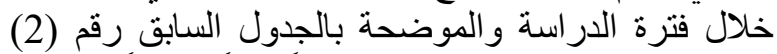

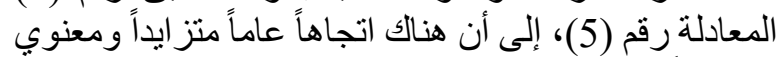

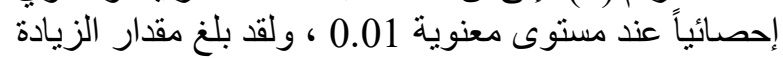

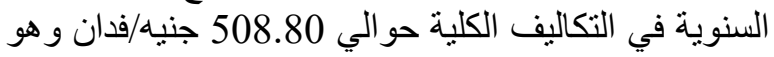

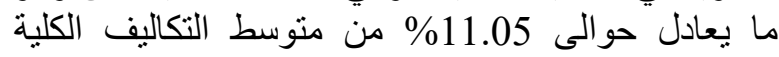
لمحصول الفول البلدي خلال تلإلك الفترة و البالغ حو الى الى 4604

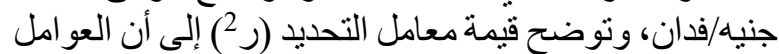

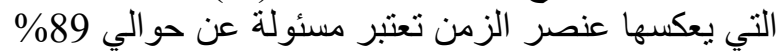

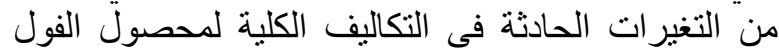

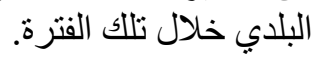
(6) الإيراد الكلي:

بدر اسة الإيراد الكلي لمحصول الفول البلدي في مصر التصر

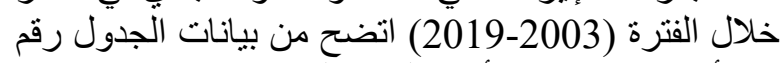

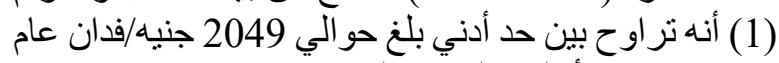

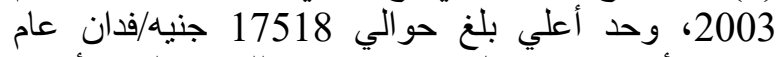

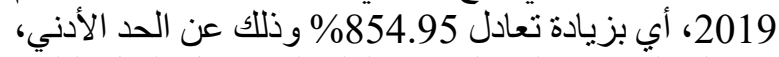

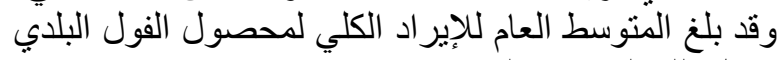

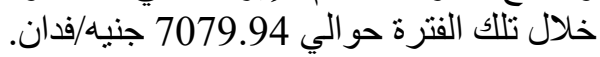

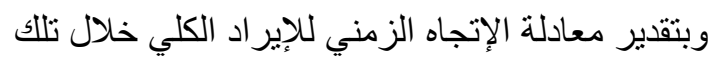

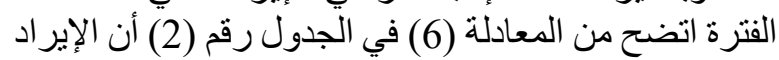

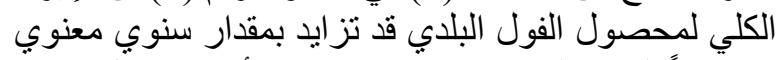

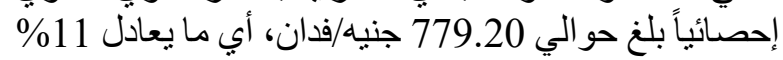

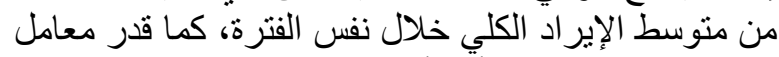

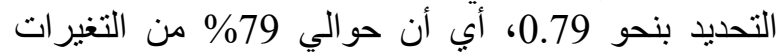

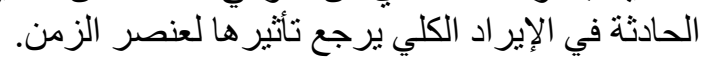

$$
\text { (7) صافي العائد: }
$$

بدر اسة صافي عائد الفدان من محصول الفول البلدي

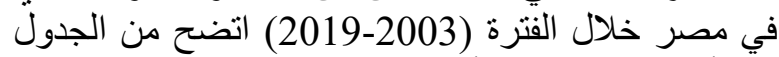

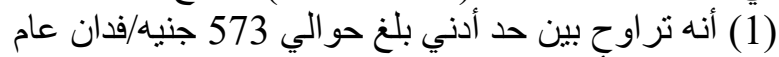

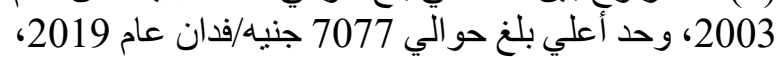
وقد بلغ المتوسط العام لصافي العائد لمحصول الفول الفي البلدي

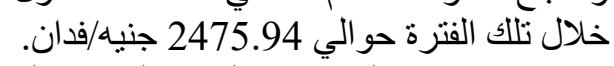
وبتقدير معادلة الإتجاه الزمني لصافي العائد خلال تلألك الكي

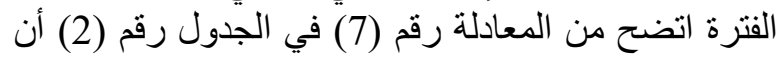

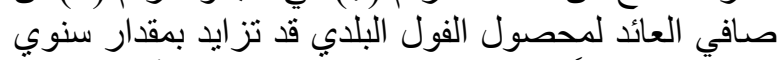

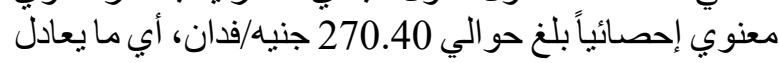
10.92\% من متوسط صافي العائد خلال نفس الفترة، ويشير الفير

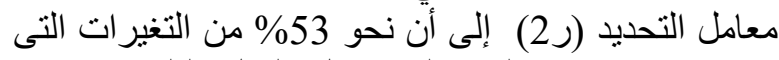

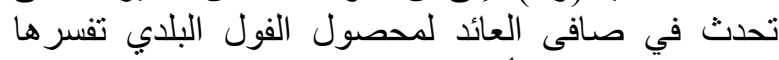

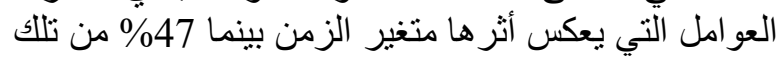

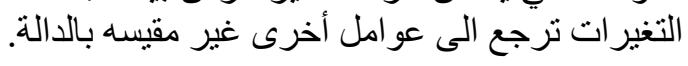
(8) نسبة الإيراد الكلي إلي التكاليف الكلية: 


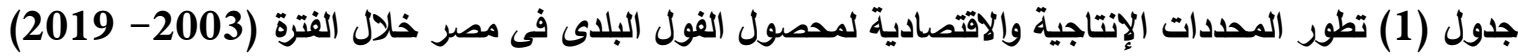

\begin{tabular}{|c|c|c|c|c|c|c|c|c|c|c|}
\hline عائد الجنيه & أربحية الوحدة & نسبة الإيراد إلى الكية & صافى العائد & (الإيراد الكلى الفدان) & (جنيه/ الفدانيف الكلية & (السعر المزرعى أردب) & (ألفت أردب) الكلى & 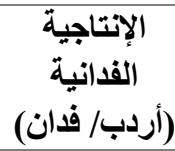 & 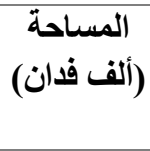 & السنة \\
\hline 0.39 & 66.62 & 1.39 & 573 & 2049 & 1476 & 218 & 2173.15 & 8.60 & 252.56 & 2003 \\
\hline 0.74 & 147.57 & 1.74 & 1306 & 3069 & 1763 & 326 & 2132.17 & 8.85 & 240.854 & 2004 \\
\hline 0.68 & 142.86 & 1.68 & 1310 & 3248 & 1938 & 331 & 1817.10 & 9.17 & 198.172 & 2005 \\
\hline 0.68 & 151.59 & 1.68 & 1381 & 3398 & 2017 & 347 & 1596.72 & 9.11 & 175.353 & 2006 \\
\hline 0.53 & 132.35 & 1.53 & 1215 & 3506 & 2291 & 353 & 1946.92 & 9.18 & 211.972 & 2007 \\
\hline 0.72 & 256.59 & 1.72 & 2376 & 5666 & 3290 & 581 & 1574.90 & 9.26 & 170.106 & 2008 \\
\hline 0.62 & 235.82 & 1.62 & 2179 & 5701 & 3522 & 573 & 1904.40 & 9.24 & 205.997 & 2009 \\
\hline 0.44 & 192.02 & 1.44 & 1565 & 5133 & 3568 & 575 & 1496.71 & 8.15 & 183.687 & 2010 \\
\hline 0.36 & 172.60 & 1.36 & 1474 & 5567 & 4093 & 596 & 1122.95 & 8.54 & 131.428 & 2011 \\
\hline 0.58 & 283.77 & 1.58 & 2605 & 7107 & 4502 & 717 & 898.53 & 9.18 & 97.906 & 2012 \\
\hline 0.54 & 265.45 & 1.54 & 2543 & 7286 & 4743 & 730 & 1005.59 & 9.58 & 104.917 & 2013 \\
\hline 0.52 & 266.77 & 1.52 & 2529 & 7359 & 4830 & 740 & 850.02 & 9.48 & 89.707 & 2014 \\
\hline 0.49 & 269.95 & 1.49 & 2524 & 7707 & 5183 & 805 & 766.05 & 9.35 & 81.934 & 2015 \\
\hline 0.13 & 92.82 & 1.13 & 853 & 7635 & 6782 & 817 & 766.40 & 9.19 & 83.356 & 2016 \\
\hline 0.43 & 396.58 & 1.43 & 3597 & 11948 & 8351 & 1286 & 1097.72 & 9.07 & 121.035 & 2017 \\
\hline 0.74 & 767.47 & 1.74 & 6984 & 16462 & 9478 & 1787 & 748.06 & 9.10 & 82.181 & 2018 \\
\hline 0.68 & 772.60 & 1.68 & 7077 & 17518 & 10441 & 1878 & 639.66 & 9.16 & 69.814 & 2019 \\
\hline 0.55 & 271.38 & $* 1.55$ & 2475.94 & 7079.94 & 4604 & 744.71 & 1325.71 & 9.07 & 147.12 & المتوسط \\
\hline 0.74 & 772.60 & 1.74 & 7077 & 17518 & 10441 & 1878 & 2173.15 & 9.58 & 252.56 & أعلى قيمة \\
\hline 0.13 & 66.62 & 1.13 & 573 & 2049 & 1476 & 218 & 639.66 & 8.15 & 69.814 & أقل قيمة \\
\hline
\end{tabular}


جدول (2) معادلات الإتجاه الزمنى العام لتطور بعض المحدات الإنتاجية والاقتصادية لمحصول الفول البلدى فى مصر خلال الفترة ( 2003 - 2019 )

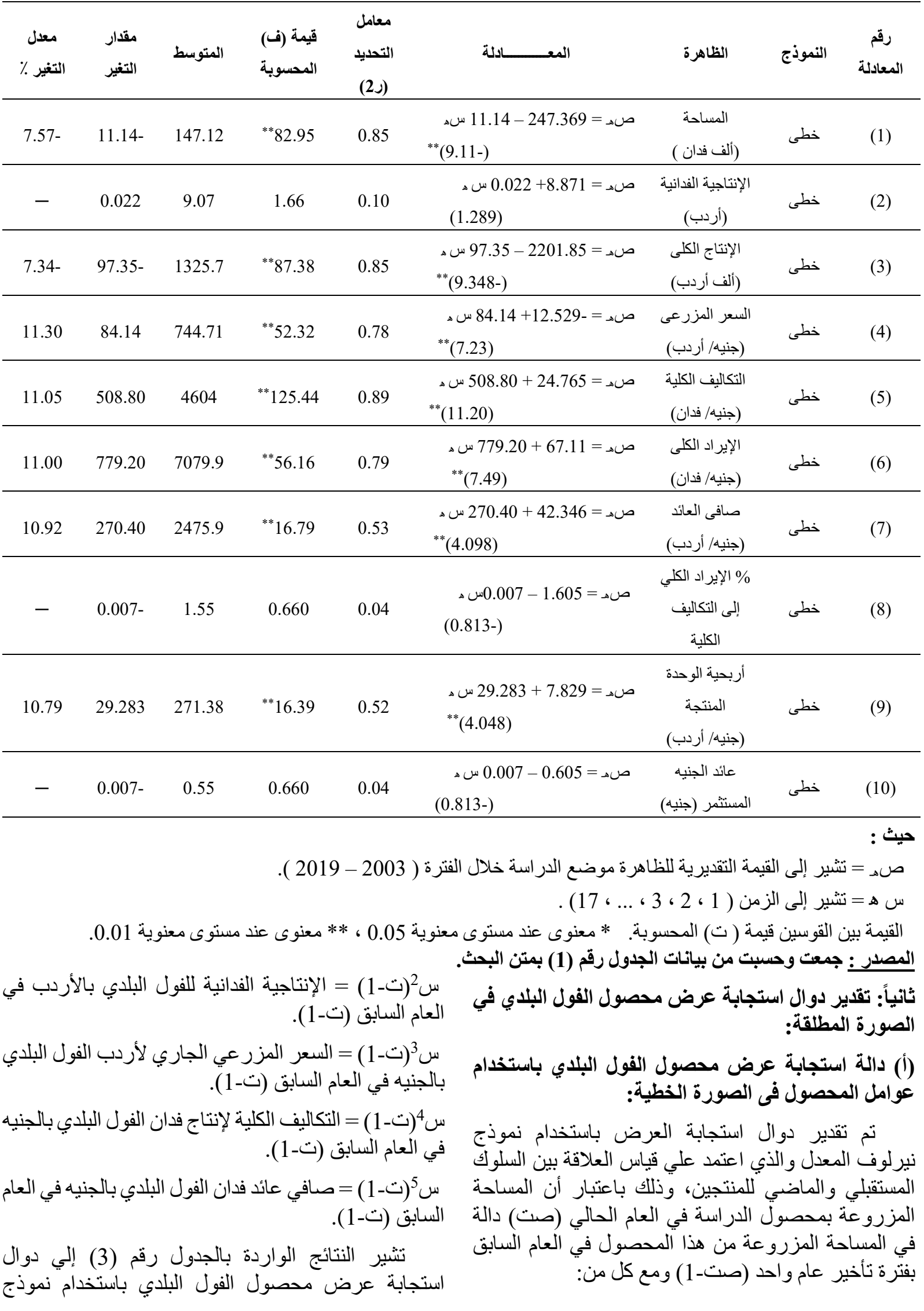


كما تشير نتائج المعادلة (2) بنفس الجدول رقم (3) إلي

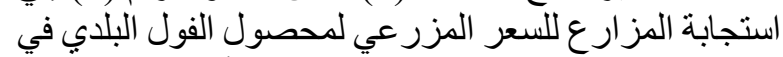

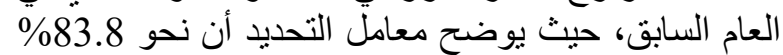

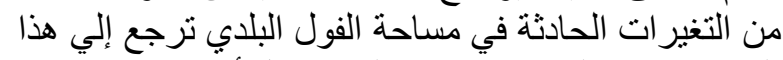

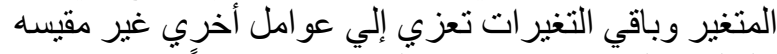
بالدالة، ولقد ثبتت معنوية النموذج إحصائياً عند مستوي

0.01

وتوضح النتائج أن زيادة السعر المزرعي للفول البلدي

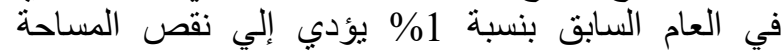
المزروعة من الفول البلدي في العام الحالي بنسبة 0.035 ألف فدان، و هذا لا يتفق مع المنطق الاقتصادي العادي.

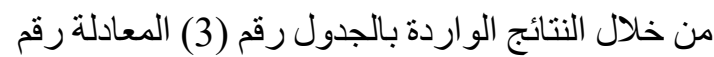

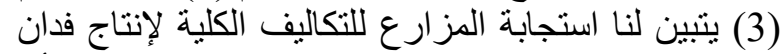

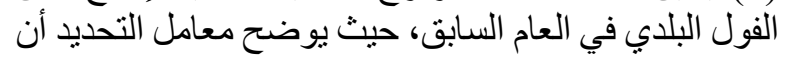

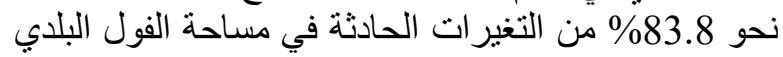

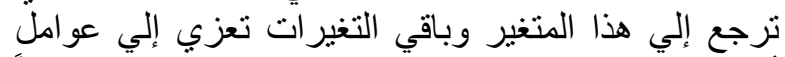
أخري غير مقيسه بالدالة، ولقد ثبت معنوية النموذج إحصائياً

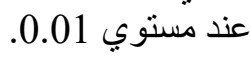

نيرلوف الديناميكي المعدل، حيث توضح المعادلة (1)

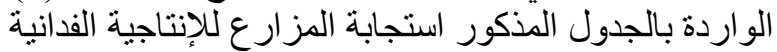

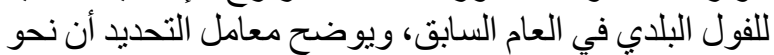

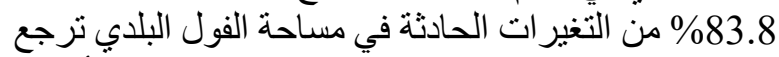

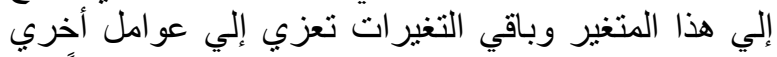
غير مقيسه بالدالة، ولقد ثبتت معنوية النموذج إحصائياً عند

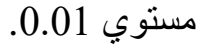

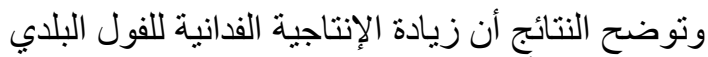

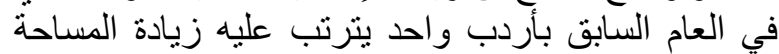

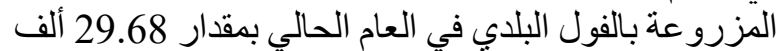

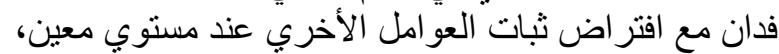

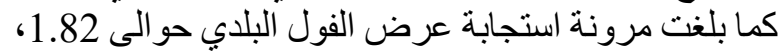

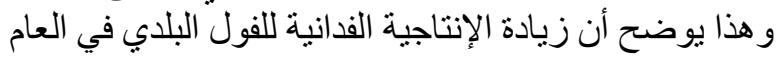

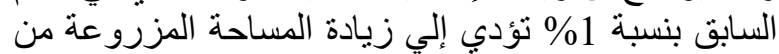

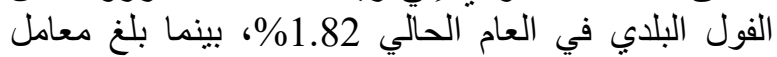

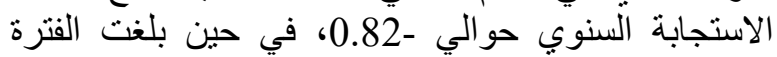

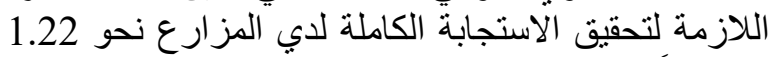

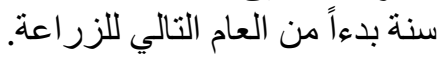

جدول (3) استجابة عرض محصول الفول البلاى طبقاً للإنتاجية الفدانية والسعر المزرعى والتكاليف الإنتاجية وصافى لفي العائد الفدانى في الصورة الخطية خلال الفترة ( 2003 - 2019 )

\begin{tabular}{|c|c|c|c|c|c|c|}
\hline الاستجابة & الاسنجابة & المرونة & قفيمة & المعدليد & المعــــــــــلة & رالمعادية \\
\hline 1.22 & $0.82-$ & 1.82 & ${ }^{* *} 36.05$ & 0.838 & 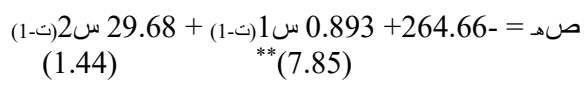 & (1) \\
\hline 0.87 & 1.15 & $0.15-$ & ${ }^{* *} 36.14$ & 0.838 & 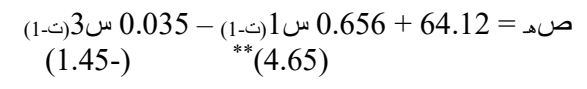 & (2) \\
\hline 0.84 & 1.19 & $0.19-$ & ${ }^{* *} 36.24$ & 0.838 & 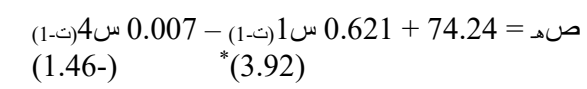 & (3) \\
\hline 0.92 & 1.09 & $0.09-$ & ${ }^{* *} 33.67$ & 0.828 & 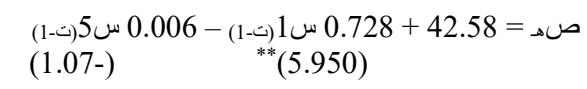 & (4) \\
\hline
\end{tabular}

صهـ = المساحة التقديرية المزروعة بالفول البلدى ألف فدان فى العام الحالى (ت) .

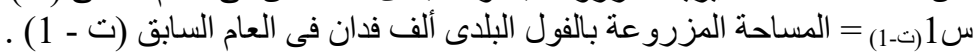

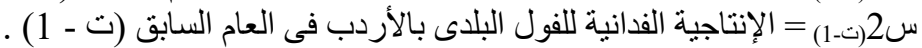

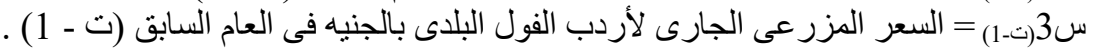

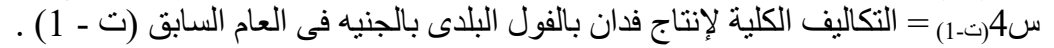

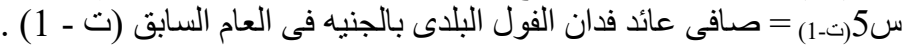

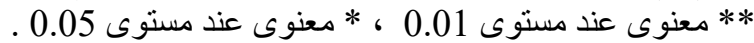

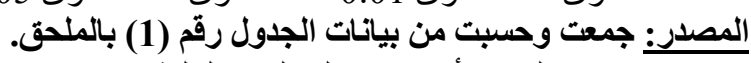

مستوي معين، كما بلغت مرونة استجابة عرض الفول البلدي

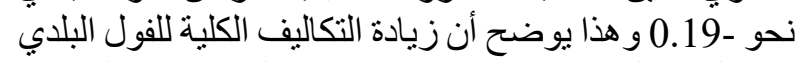

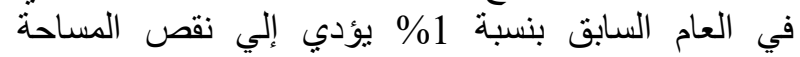
المزروعة من الفول البلدي في العام الحالي بنسبة -0.19\%؛ لفية

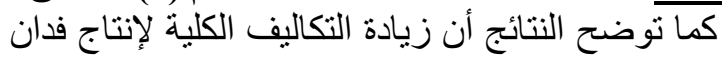

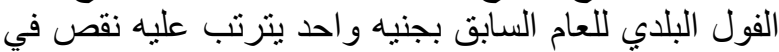

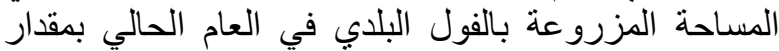
0.007 ألف فدان مع افتراض ثبات العول العل الأخري عند العند 
بينما بلغ معامل الاستجابة السنوي حو الي 1.19، في حين (ب) دالة استجابة عرض محصول الفول البلاي في الصورة

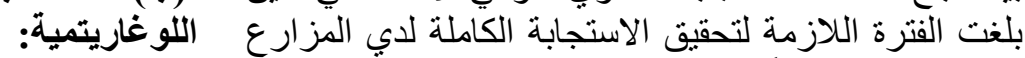

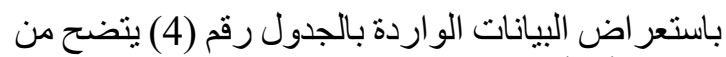

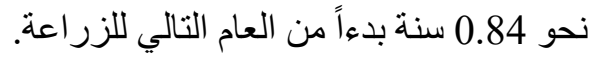

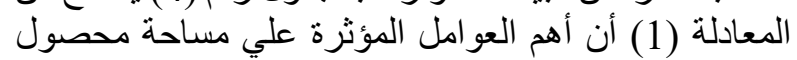

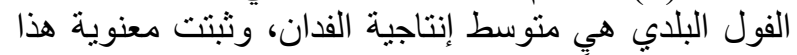

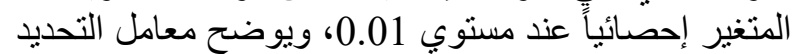

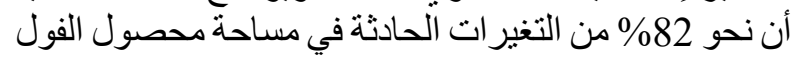

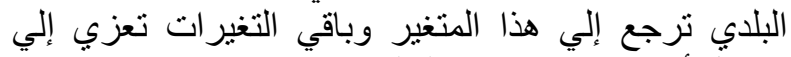
عو امل أخري غير مقيسه بالدالة.

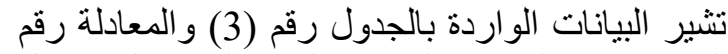

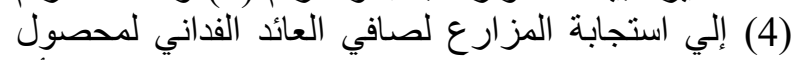

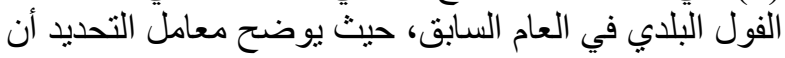

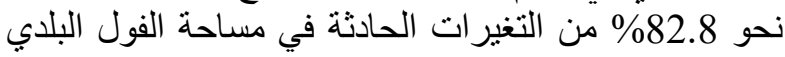

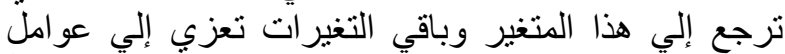

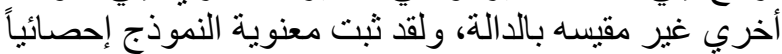

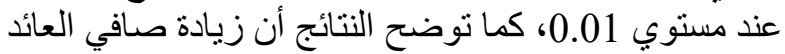

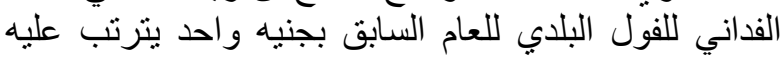

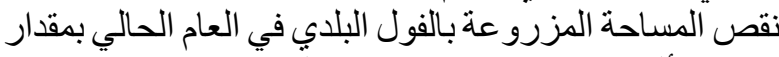
0.006 ألف فدان، وهذا لا يتفق مع المنظقِ الاقتصادي.

جلول (4) استجابة عرض محصول الفول البلاى طبقاً للإنتاجية الفدانية والسعر المزرعى والتكاليف الإنتاجية وصافى العائد الفدانى في الصورة (4) اللوغاريتمية المزدوجة خلال الفترة (2003 - 2019 )

\begin{tabular}{|c|c|c|c|c|c|c|}
\hline الاستجابة & الاسنجابة & المرونة & قَّ) & التحدليد & المعـــــــــــلة & المعادلة \\
\hline
\end{tabular}

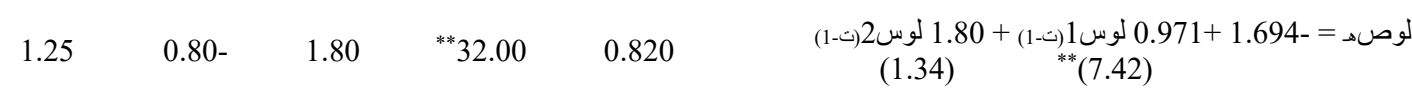

\begin{tabular}{|c|c|c|c|c|c|c|}
\hline 0.76 & 1.32 & $0.32-$ & **39.08 & 0.848 & 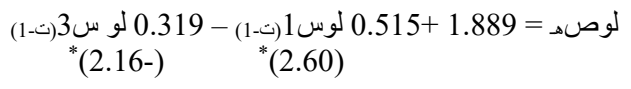 & (2) \\
\hline 0.75 & 1.34 & $0.34-$ & ${ }^{* *} 38.05$ & 0.845 & 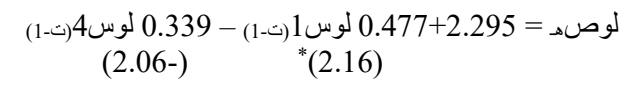 & (3) \\
\hline 0.85 & 1.18 & $0.18-$ & ${ }^{* *} 36.66$ & 0.840 & 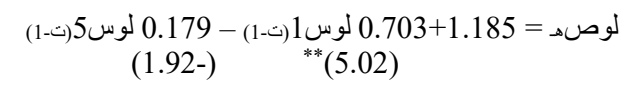 & (4) \\
\hline \multicolumn{7}{|c|}{ 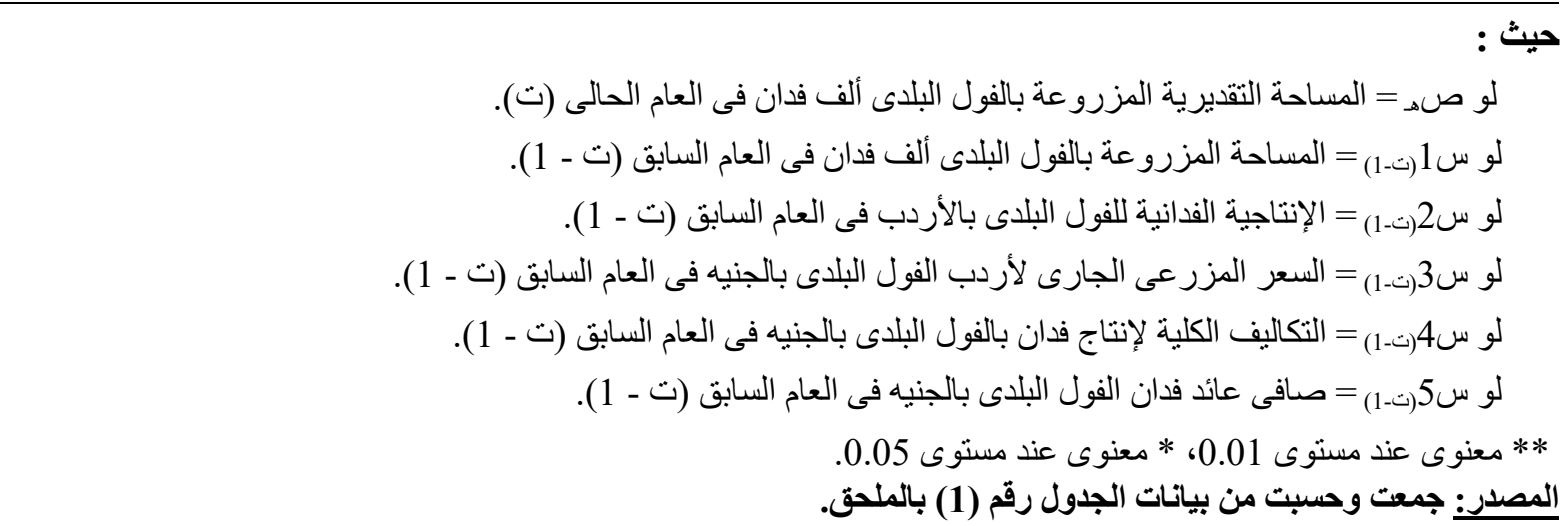 } \\
\hline
\end{tabular}

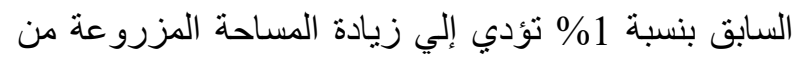

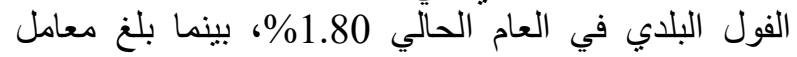

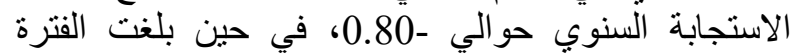

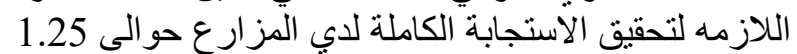

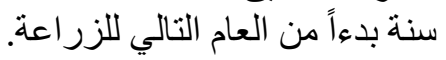

وتوضح النتائج أن زيادة الإنتاجية الفدانية للفول البلاي

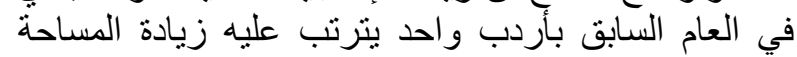

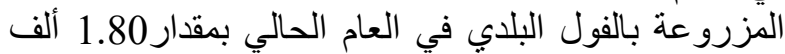

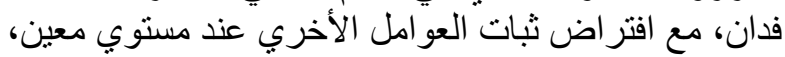

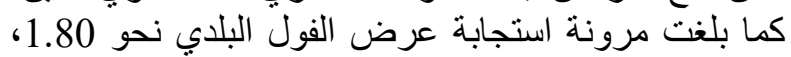

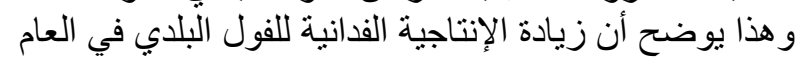


ص هـ = المساحة المزروعة بالفول البلاي بالألف فدان في

السنة (ت) . (المن

س1 (ت-1) =السعر المزرعي للفول البلدي بالجنيه في العام

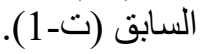

س2 (ت-1) = السعر المزرعي للعدس بالجنيه في العام السابق ) (1)

س³ (ت-1) = السعر المزرعي للشعبر بالجنيه في العام السابق

س4 (ت-1) = السعر المزرعي للقمح بالجنيه في العام السابق

سك (ت-1) = السعر المزرعي للبرسيم بالجنيه في العام السابق

س6 (ت-1) = السعر المزرعي للبنجر بالجنيه في العام السابق

س" (ت-1) = السعر المزرعي للحمص بالجنيه في العام السابق

س ${ }^{8}$ (ت-1) = السعر المزرعي لبذرة الكتان بالجنيه في العام

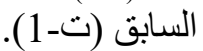

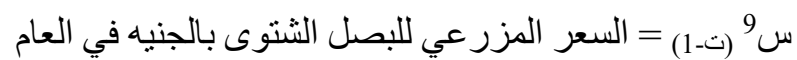

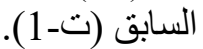

س01 (ت-1) = السعر المزرعي للثوم بالجنيه في العام السابق

من خلال نتائج التحليل الو اردة بالجدول رقم (5) المعادلة

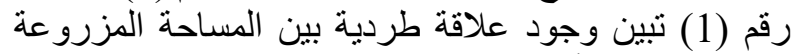

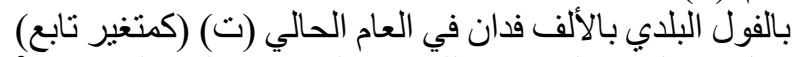

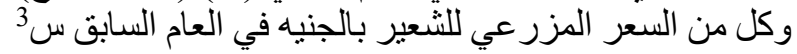

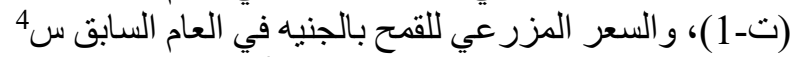

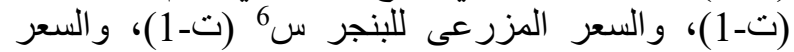

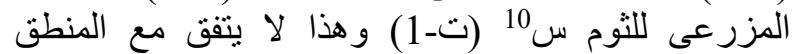
الاقتصادي.

كما يتضح من نفس النموذج وجود علاقة عكسية منطقية

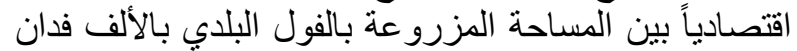

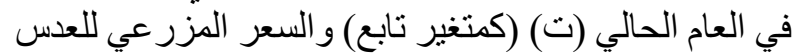

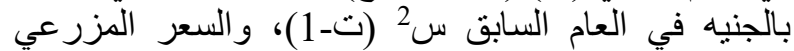

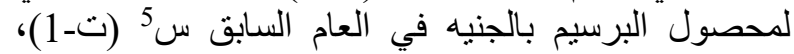

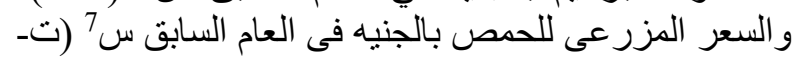

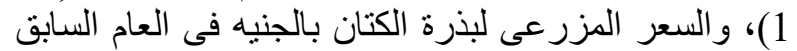

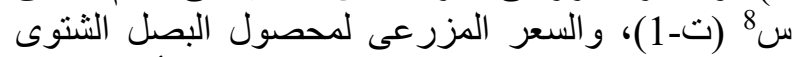

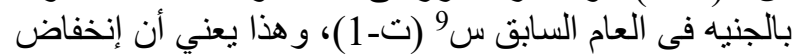

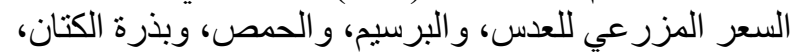

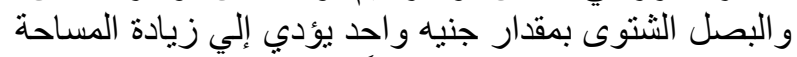

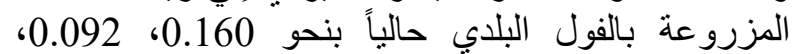

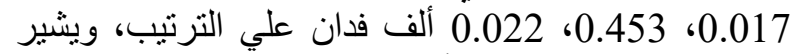
معامل التحديد المعدل إلي أن 942\% من التئير التيرات في مساحة

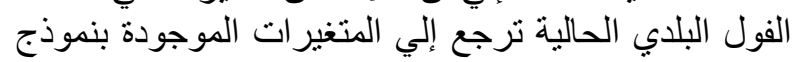

كما تثير نتائج المعادلة رقم (2) بالجدول رقم (4) إلي الي

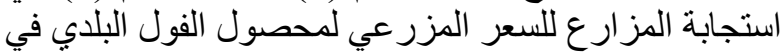

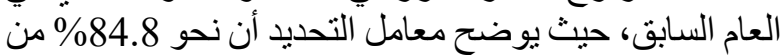

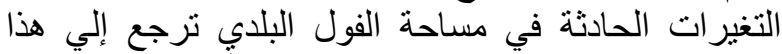

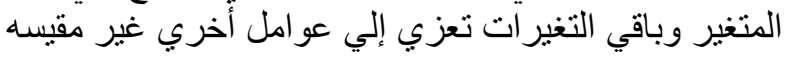

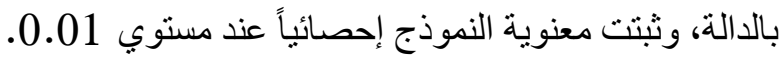
وتوضح النتائج أن زيادة السعر المزرعي لإنتاج فدان

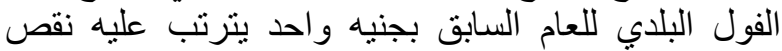

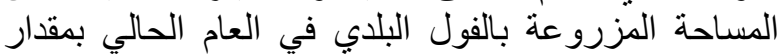

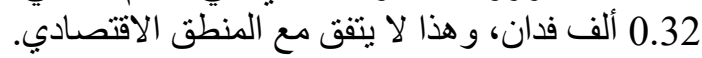

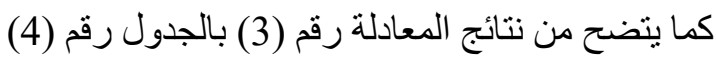

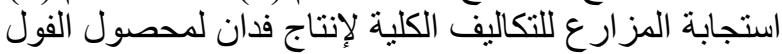

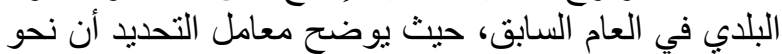

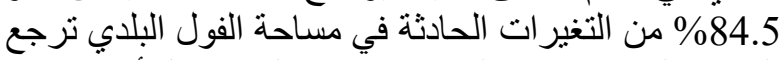

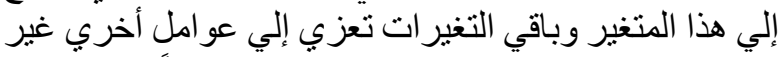

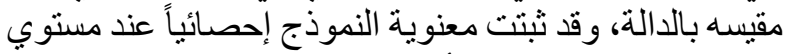

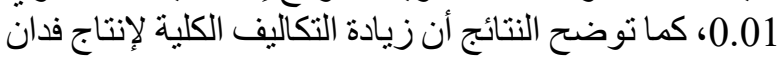

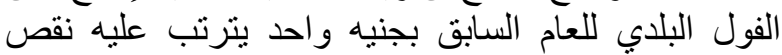

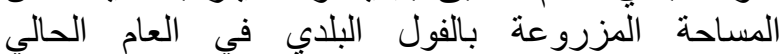

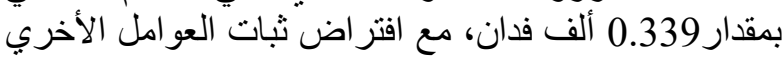

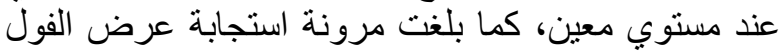

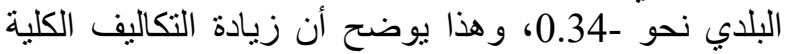

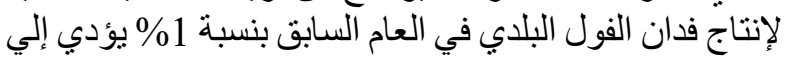

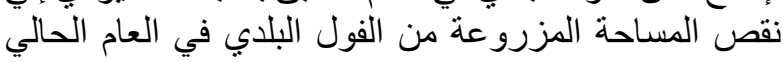

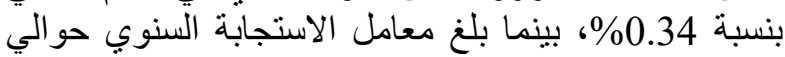

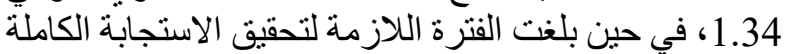

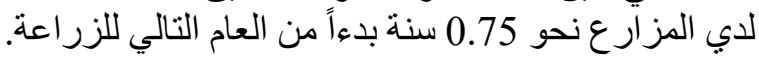

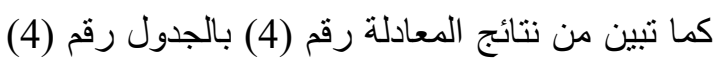

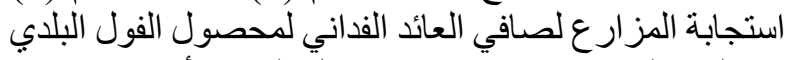

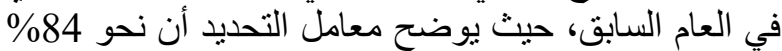

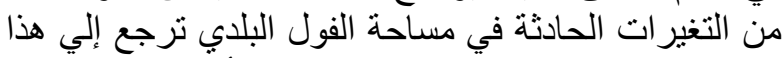

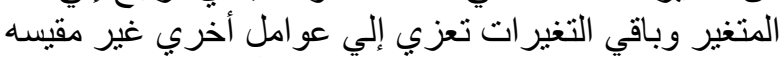

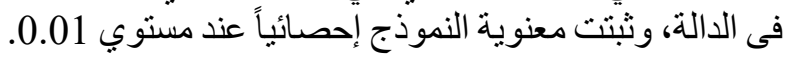

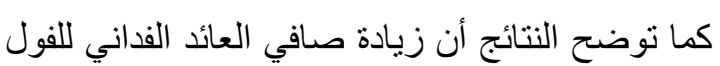

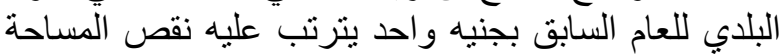

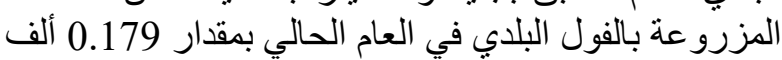
فدان، وهذا لا يتفق مع ألّنظق الاقتصادي.

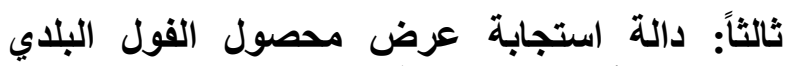
باستخدام الأسعار المزرعية للمحاصيل:

(أ) دالة استجابة عرض محصول الفول البلدي في الصورة

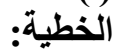

يتضح من الجدول رقم (2 بالملحق) أسعار أهم المحاصيل

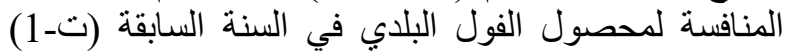

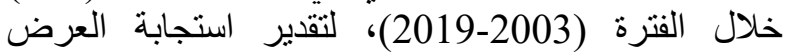
لمحصول الفول البلدي باستخدام نموذج الإنحدار المتعدد و الإنحدار المتعدد المرحلي في صورته الخطية كان من خلال: 
الحالي (ت) (كمتغير تابع) و السعر المزرعي للبرسيم بالجنيه

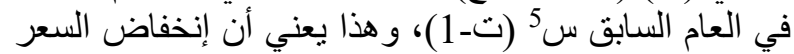

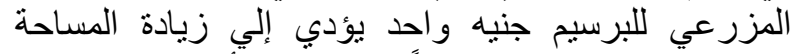
المزروعة بالفول البلدي حالياً بنحو

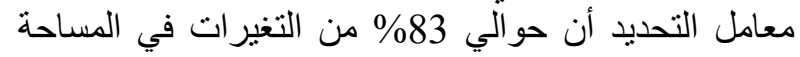

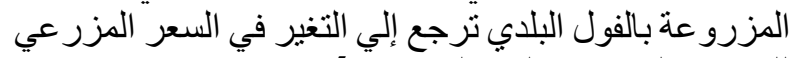

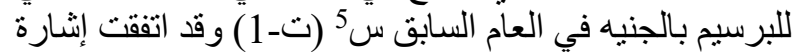
معامل الإنحدار المقدر مع المنطق الاقتصادي.
الاستجابة، ويرجع باقي التغيرات إلي متغير ات أخري لم الم تدخل في النموذج، في حين أن النموذج ككل معنوي عند الند الني

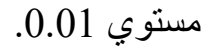

وباستخدام أسلوب الإنحدار المتعدد المرحلي في صورته المانه الخطية لتقدير دالة استجابة عرض الإندار الفول البلدي البرحي خلال الفترة

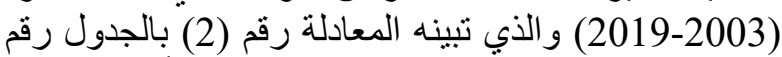
(5) يتضح من نتائج النموذج أنه معنوي إحصائياً عند مستوي

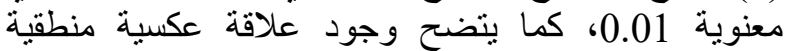
اقتصادياً بين المساحة المزروعة بالفول البلدي في العام

جدول (5) تقدير استجابة العرض لمحصول الفول البلاى باستخدام متغير المساحة مع أسعار أهم المحاصيل المنافسة له فى السنة السابقة فى الصورة الخطية خلال الفترة (2003-2019)

\begin{tabular}{|c|c|c|c|c|}
\hline ف & معامل التحديد & 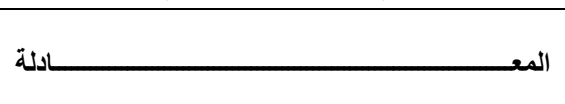 & 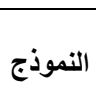 & 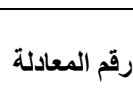 \\
\hline & & 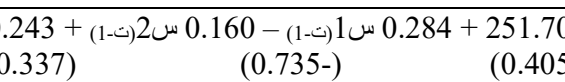 & & \\
\hline
\end{tabular}

الإحدار المتعدد

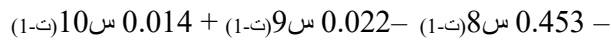

$(0.500) \quad(0.109-) \quad(1.450-)$

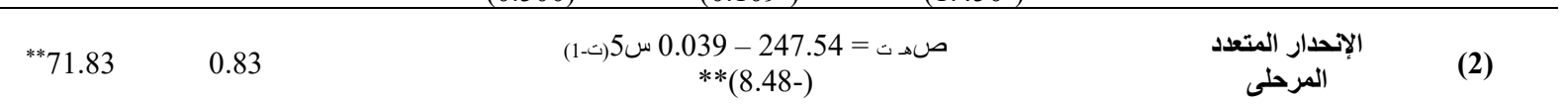

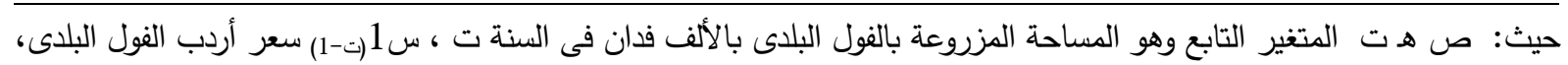

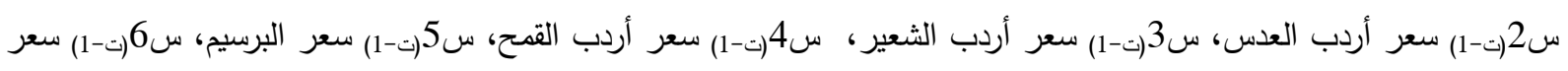

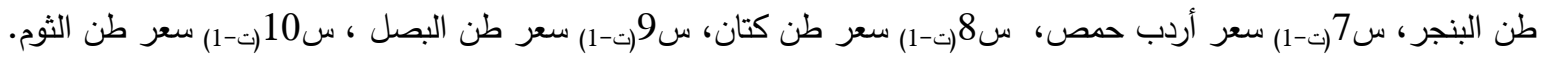

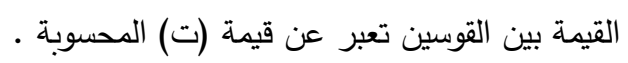

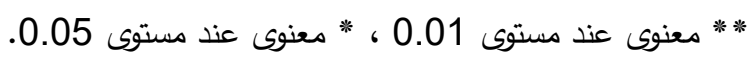
المصدر: جمعت وحسبت من بيانات الجدول رقم (2) بالملحق.

لوس2 (ت-1) = السعر المزرعي للعدس بالجنيه في العام السابق (ت-1-1).

لوس3 (ت-1) = السعر المزرعي للشعير بالجنيه في العام السابق (ت-1-1) (ت) (1-)

لوس4 (ت-1) = السعر المزرعي للقمح بالجنيه في العام السابق (ت-1-1) (1-) (1-) لوس5 (ت-1) = السعر المزرعي للبرسيم بالجنيه في العام السابق (ت-1-1). لوس6 (ت-1) = السعر المزرعي للبنجر بالجنيه في العام

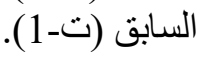
لوس7 (ت-1) = السعر المزرعي للحمص بالجنيه في العام

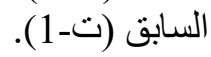

\section{(ب) دالة استجابة عرض محصول الفول البلدي في الصورة اللوغاريتمية المزدوجة لمنة}

يتضح من الجدول رقم (2 بالملحق) أسعار أهم المحاصيل

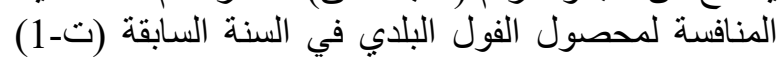

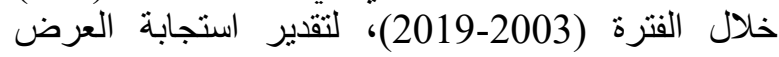

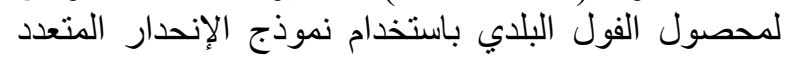

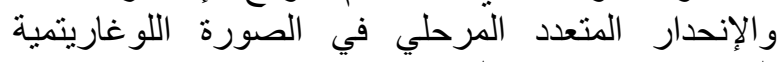

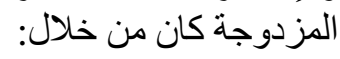
لوص هـ = المساحة المزروعة بالفول البلدي بالألف فدان في السنة (ت) لون لوس1 (ت-1) =السعر المزرعي للفول البلدي بالجنيه في

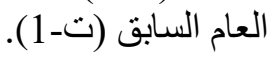




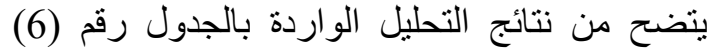

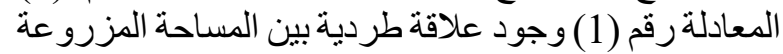

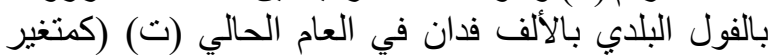

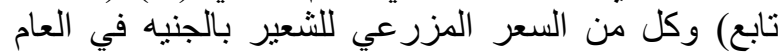

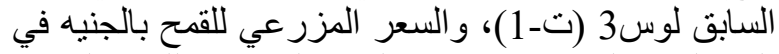

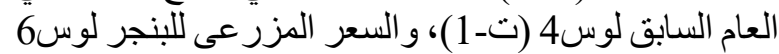

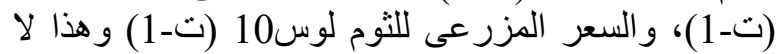
يتفق مع المنطق الاقتصادي.
لوس8 (ت-1) = السعر المزرعي لبذرة الكتان بالجنيه في

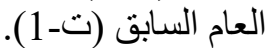

لوس9 (ت-1) = السعر المزرعي للبصل الثتوى بالجنيه في

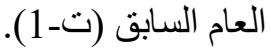

لوس10 (ت-1) = السعر المزرعي للثوم بالجنيه في العام السابق (ت-10) (1) - (1)

جدول (6) تقدير استجابة العرض لمحصول الفول البلدى باستخدام متغير المساحة مع أسعار أهم المحاصيل المنافسة

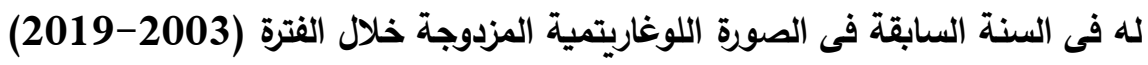

\begin{tabular}{|c|c|c|c|c|}
\hline ف & التحدلد & المعــــــــــــــــ & النموذج & المعادلة \\
\hline${ }^{* *} 7.06$ & 0.92 & 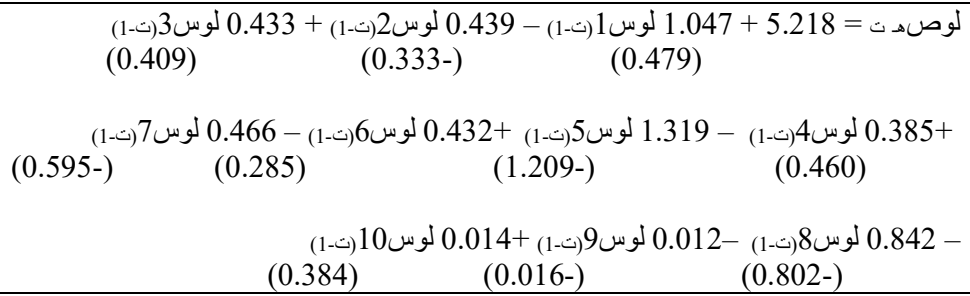 & المتعدد & (1) \\
\hline${ }^{* *} 103.06$ & 0.87 & 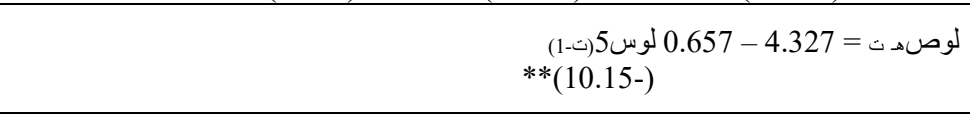 & المتردد الإتحدار & (2) \\
\hline
\end{tabular}

حيث: لوص هـ ت المتغير التابع وهو المساحة المزروعة بالفول البلدى بالألف فدان فى السنة ت ، لوس1ا(ت-1) سعر أردب الفول

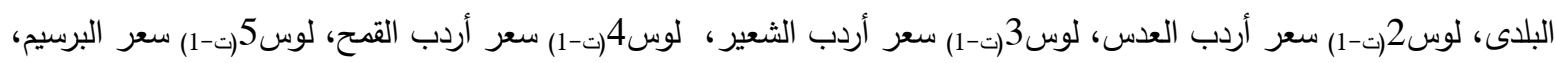

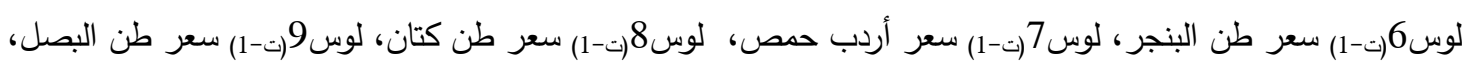

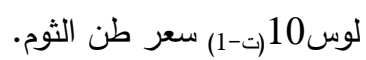

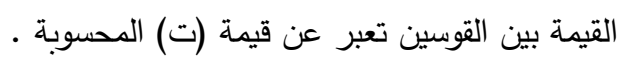

التغير ات إلي متغير ات أخري لم تدخل في النموذج، في حين

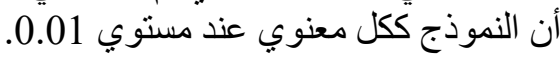

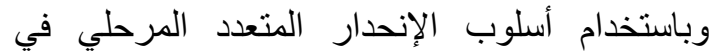

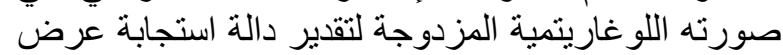

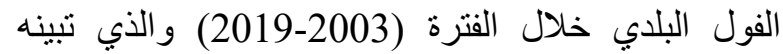

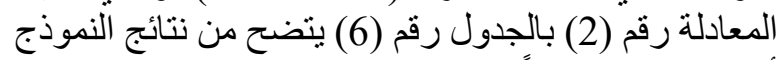

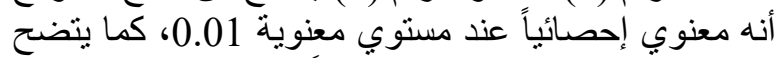

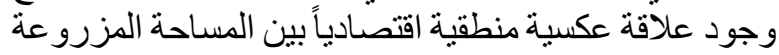

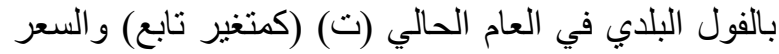

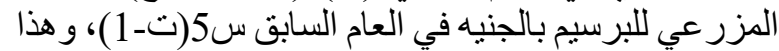

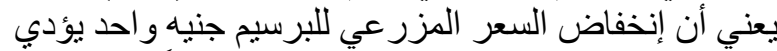
إلي زيادة المساحة المزرو عة بالفول البلاي حالياً بنحو 0.22

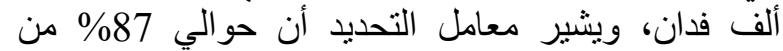

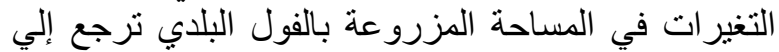

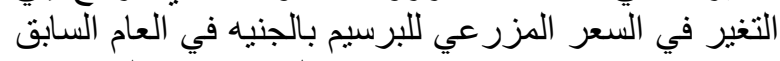
س5 (ت-1) وقد اتفقت إنثارة معامل الإنحدار المقدر مع العام العابر

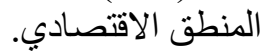

* * معنوى عند مستوى 0.01 ، * معنوى عند مستوى 0.05. المصدر: جمت وحسبت من بيانات الجدول رقم (2) بالملحق.

ومن خلال نتائج التحليل يتضح من نفس النموذج وجود

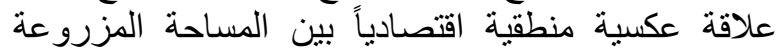

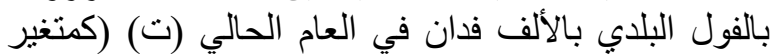
تابع) و السعر اللإي بلالفرعي للعدس بالجنيه في العام العام السابق

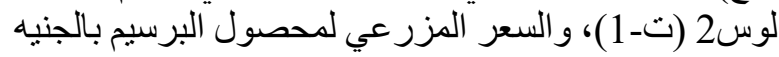

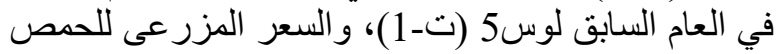

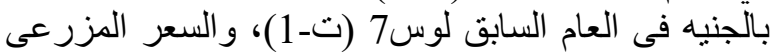

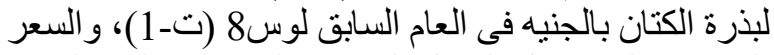

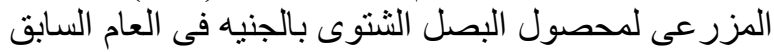

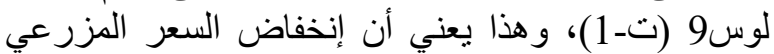

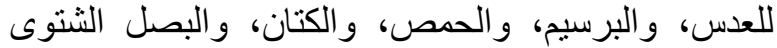

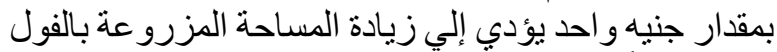

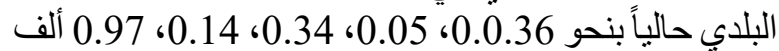

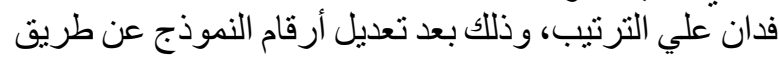

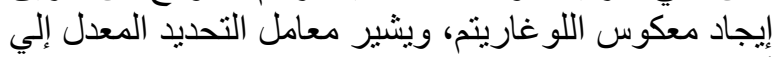

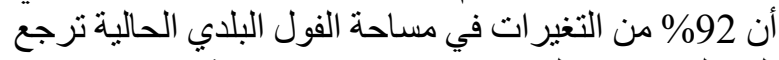

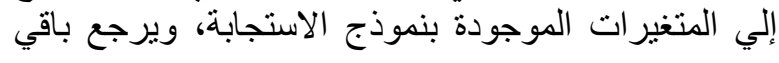


السعرية للفول البلدي / الشعير ، و النسبة السعرية للفول البلدي

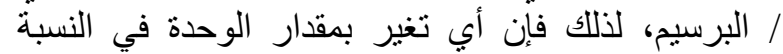

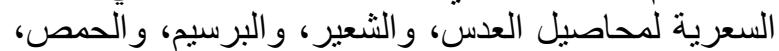

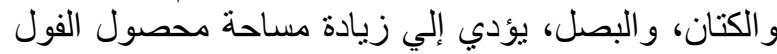

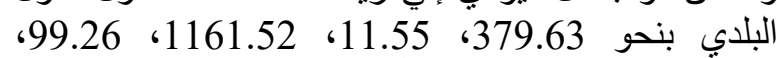

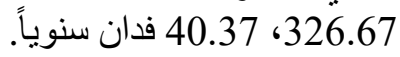

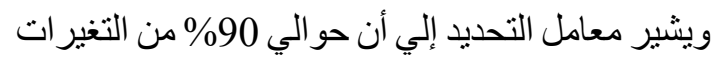

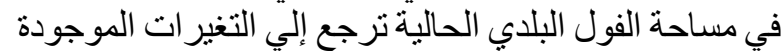

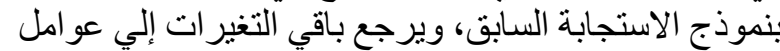

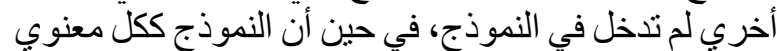

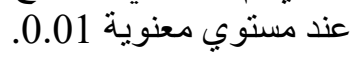

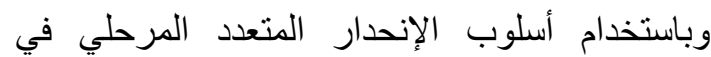

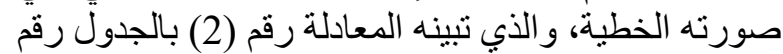

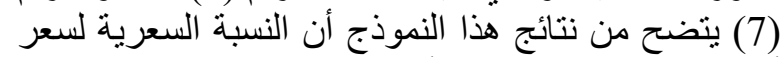

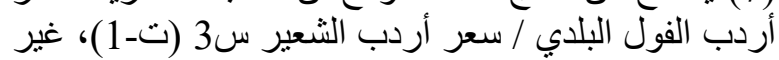

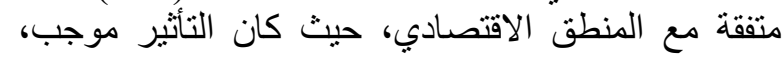

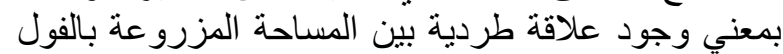

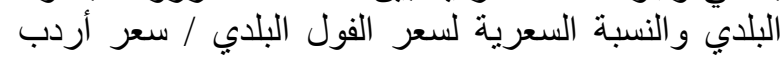

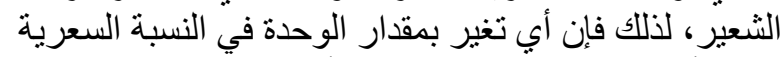

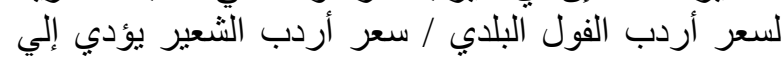
زيادة المساحة المزرو عةٌ بالفول البلاي بنحو 85.598 ألف الفي فدان سنوياً.

كما اتضح من نتائج هذا النموذج أن النسبة السعرية النقائ

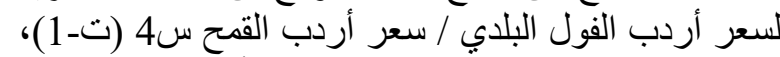

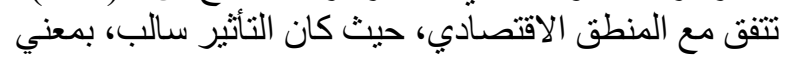

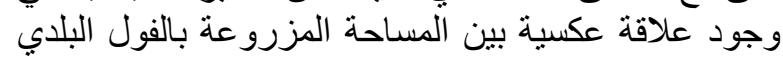

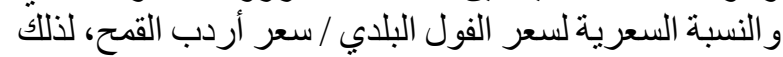

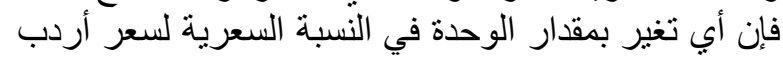

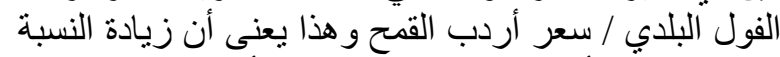

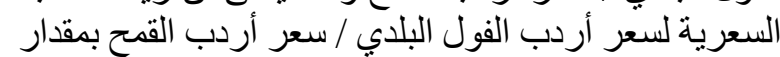

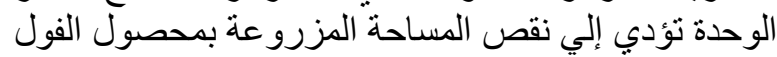
البلدي بمقدار 65.903 ألف فدان.
رابعاً: تقدير دوال استجابة عرض محصول الفول البلدي في الصورة النسبية دوال النجابة

(أ) دالة استجابة عرض محصول الفول البلدي في الصورة

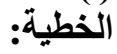

توضح نتائج التحليل بالجدول (7)، و المعادلة (1)

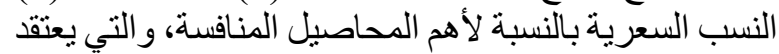

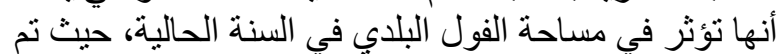

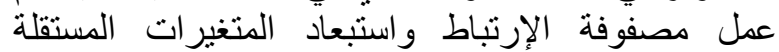

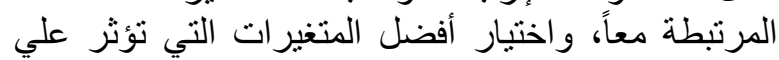

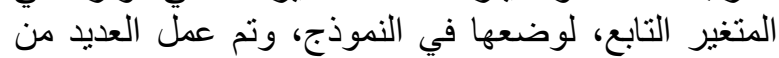

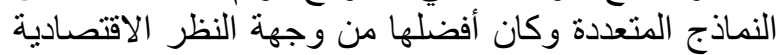

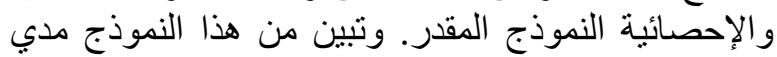

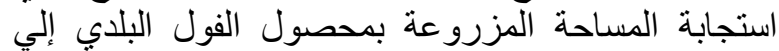

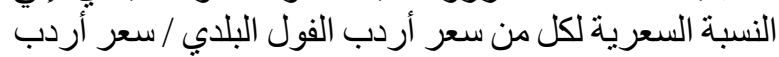

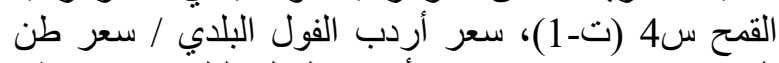

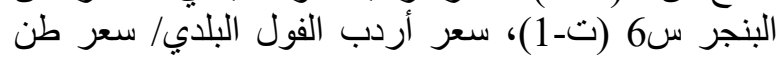

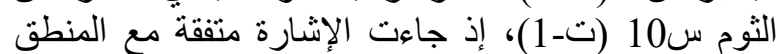

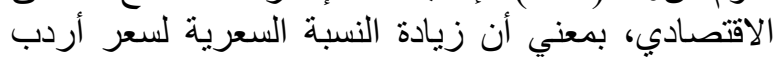

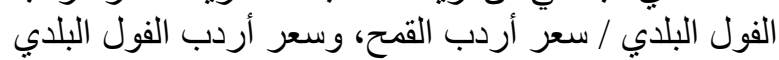

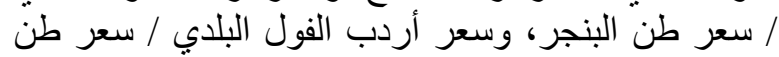

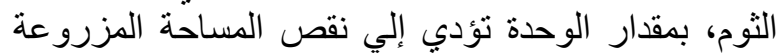

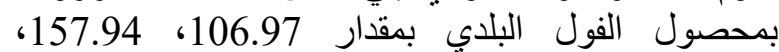
212.61 ألف فدان على ألترتيب.

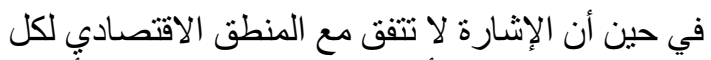

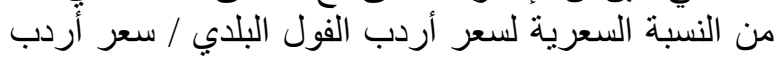

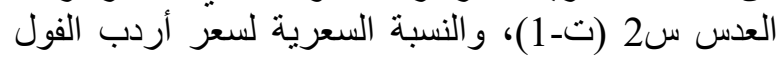

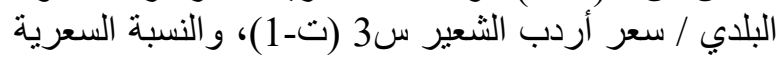

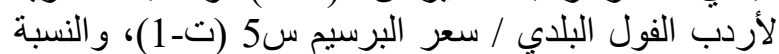

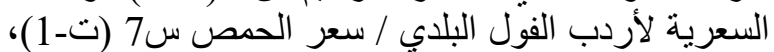

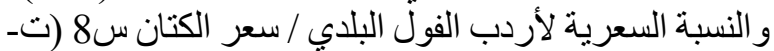

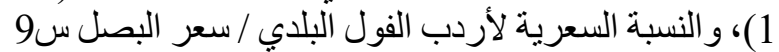

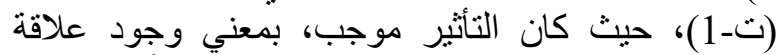
طردية بين المساحة المزرو عة بالفول البلدي وكلاً من النسبة عالِّة

جدول (7) تقدير استجابة العرض لمحصول الفول البلدى باستخدام متغير المساحة مع الأسعار النسبية لأهم المحاصيل

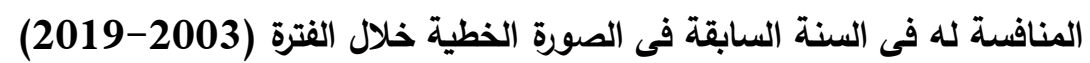

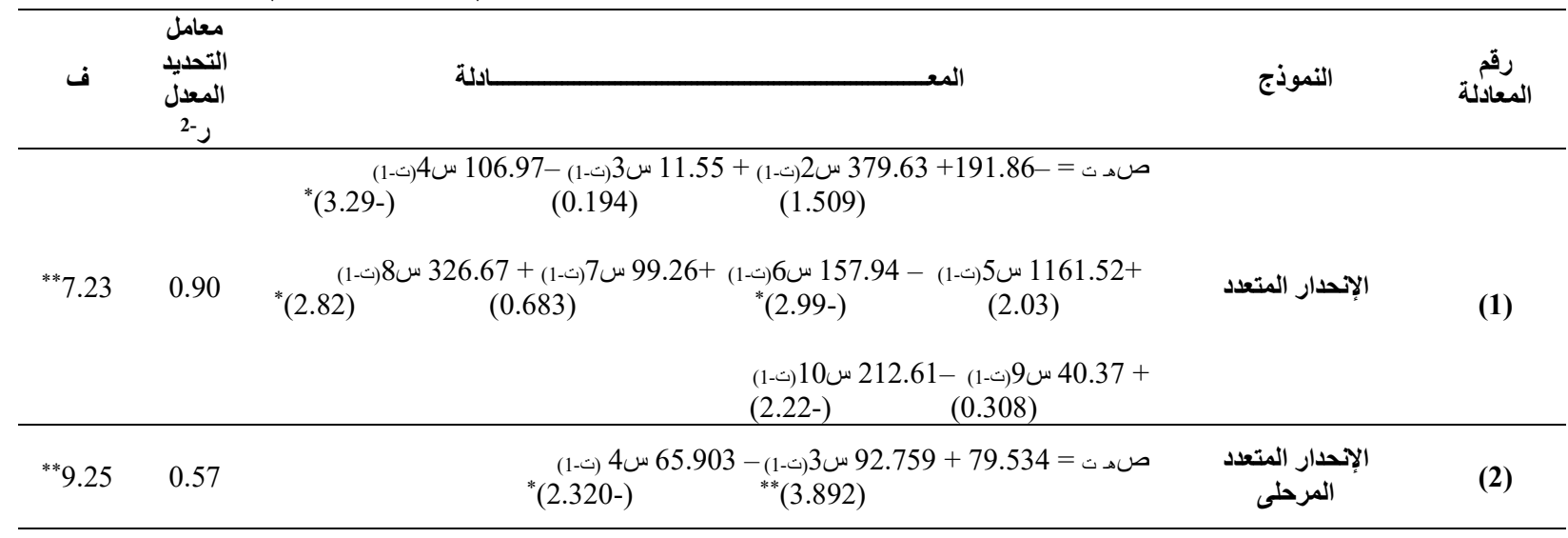




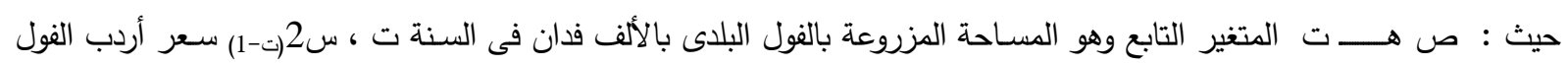

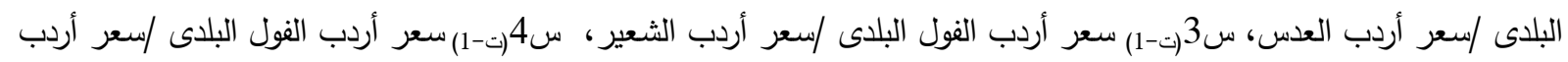

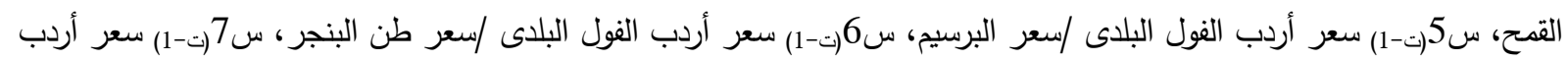

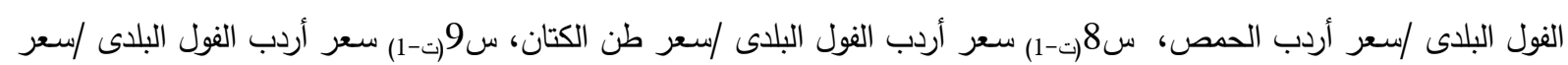

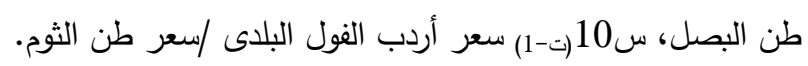
القيمة بين القوسين تعبر عن قيمة ( ت ) الححسوبة .

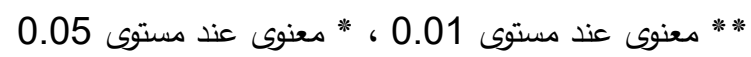

بمقدار الوحدة تؤدي إلي نقص المساحة المزرو عة بمحصول

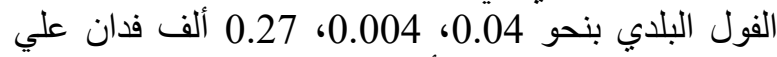

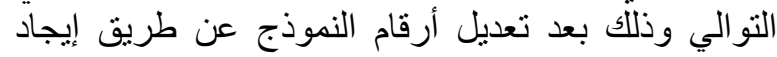

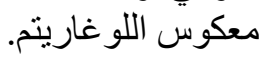

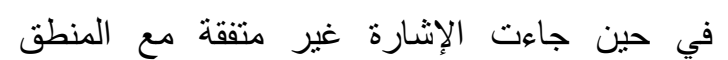

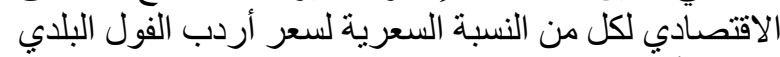

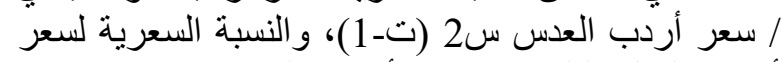

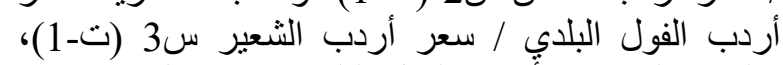

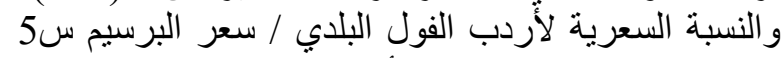

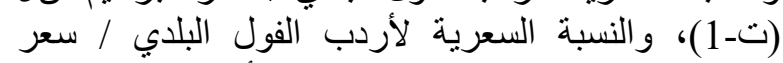

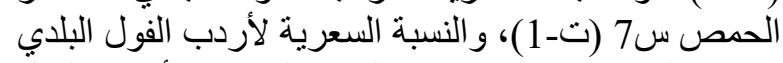

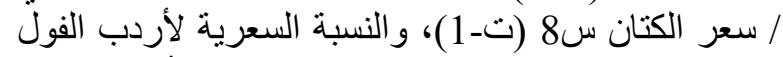

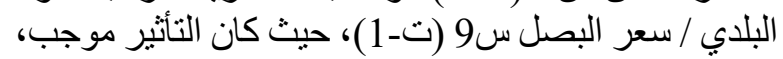

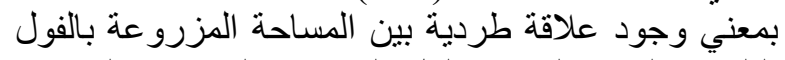

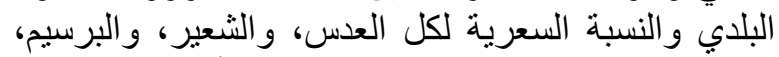

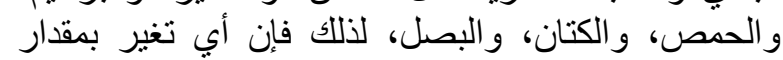

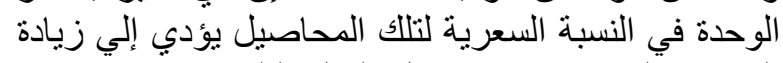

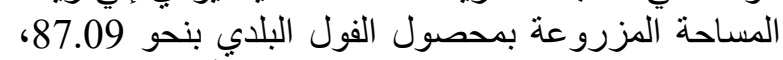

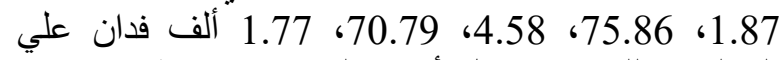
التوالي وذللك بعد تعديل أرقام النموذج عن طريق إيجاد معكوس اللوغاريتم.

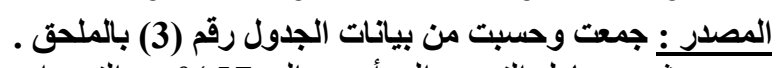

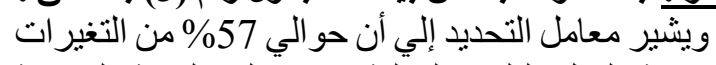

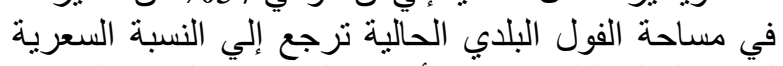

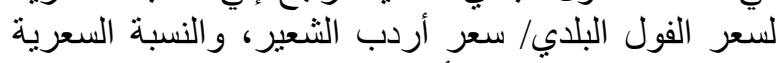

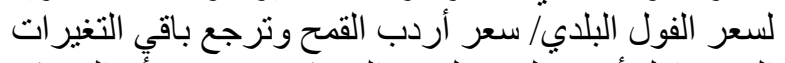

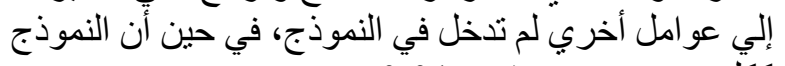

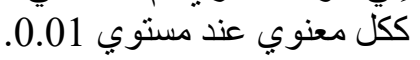

\section{(2) دالة استجابة عرض محصول الفول البلاي في الصورة}

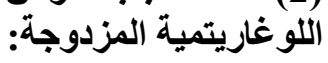

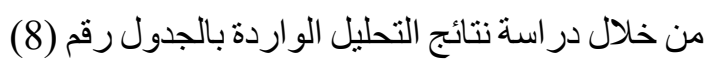

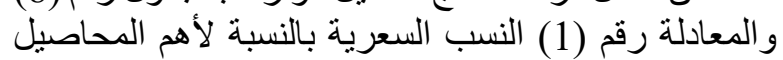

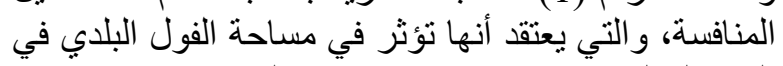

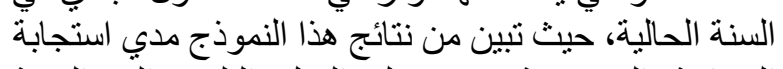

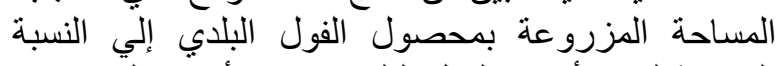

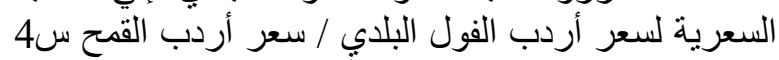

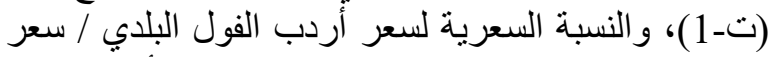

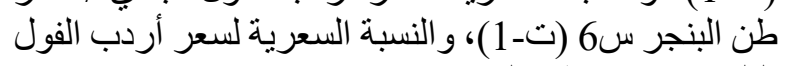

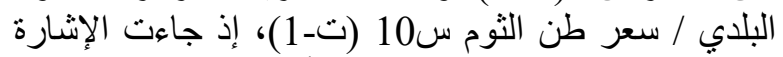

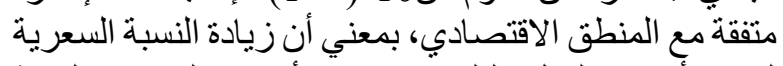

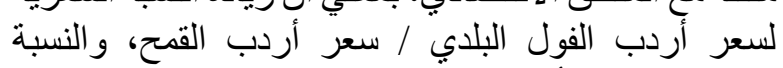

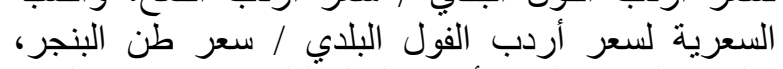

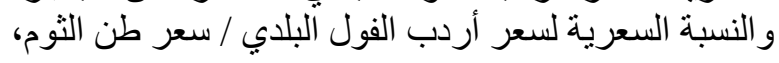

جدول (8) تقدير استجابة العرض لمحصول الفول البلدى باستخدام متغير المساحة مع الأسعار النسبية لأهم المحاصيل

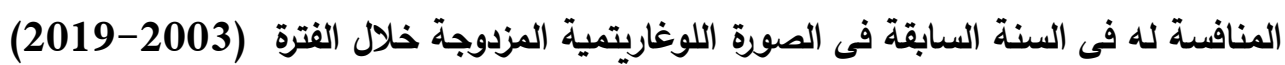

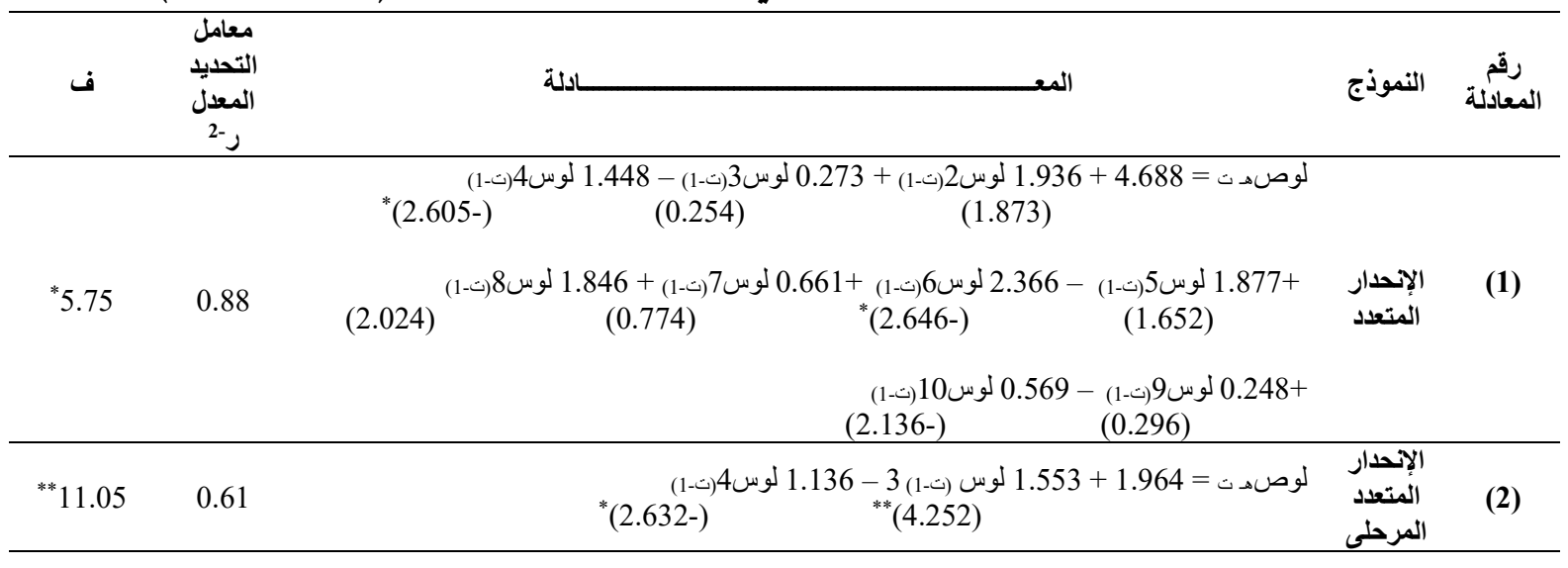

حيث : لوص هـ ت المتغير التابع وهو المساحة المزروعة بالفول البلدى بالألف فدان فى السنة ت ، لوس2:-1-1 سعر أردب الفول

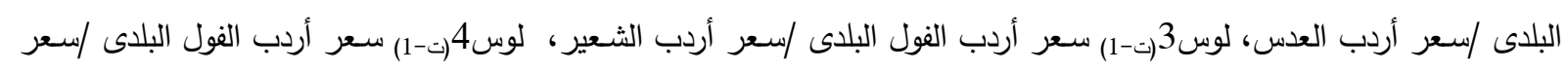

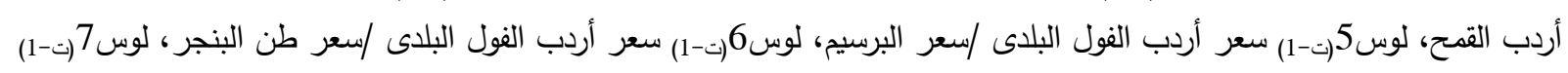


سعر أردب الفول البلدى /سعر أردب الحمص، لوس8(ت-1) سعر أردب الفول البلدى /سعر طن الكتان، لوس9 (ت-1) سعر أردب الفول

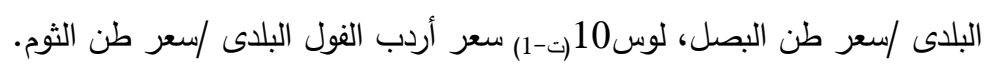

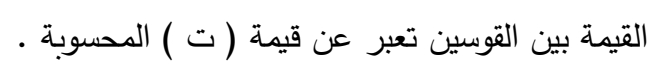

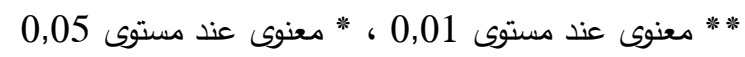

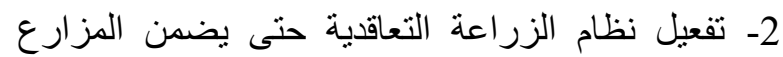

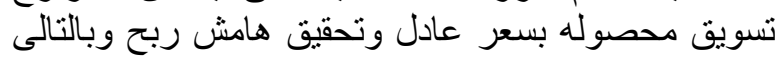
تحفيز المزارعين على زر اعة ذله اللك المحصول.

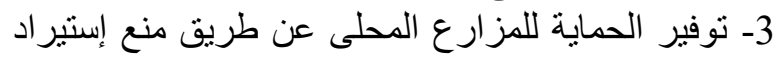
المحصول في موسم الحصناد.

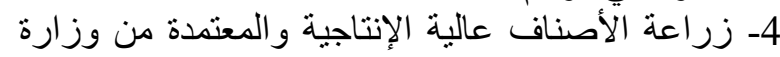

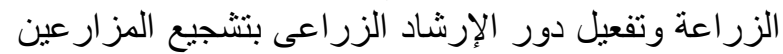
على زر اعة تلك الأصناف. 5- عدم الإسر اف في إستخدام الأسمدة و المبيدات حتي يمكن

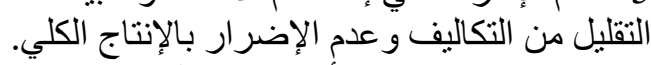

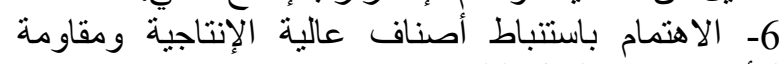

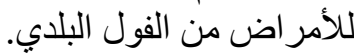

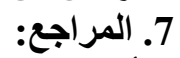

1- أمانى عبد المعز عبد المعبود وآخرون (2019). دراسة

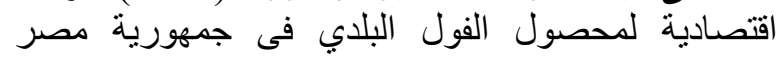
العربية، مجلة الزقازيق للبحوث ألزر اعية، المجلد (46)،

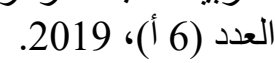

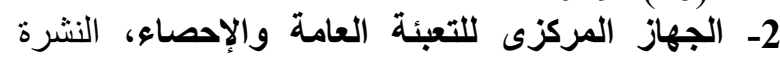

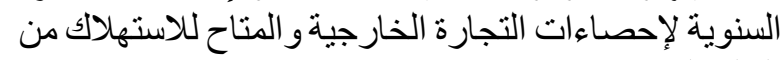

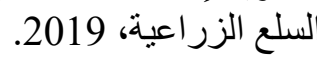

3- سوزان عبد المجيد أبو المجد على (2015). دراسة

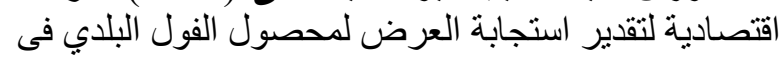

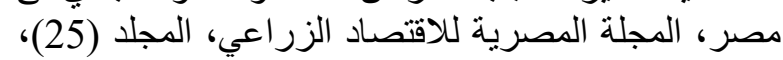

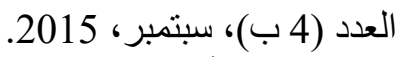

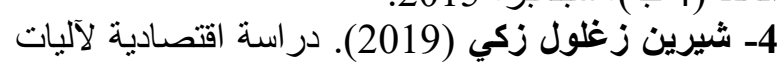

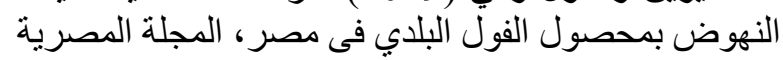

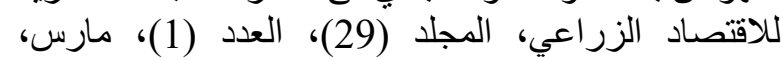
2019

5- صفية عمر محمد، منى محمود محمد (2016). دراسة

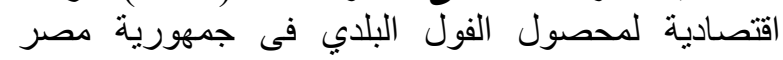

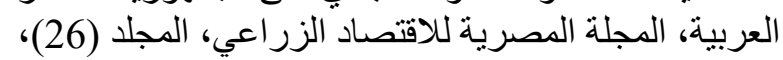
6- العدد (3)، سبتمبر، المجل والمصرية 2016.

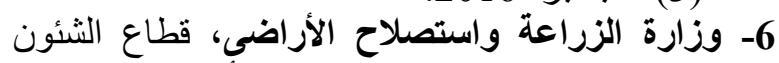

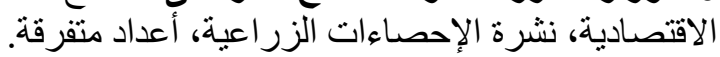

7. Eliw, M., Mottawea, A., and El-Shafei, A. (2019), Estimating Supply Response of Some Strategic Crops in Egypt Using ARDL Model. South Asian Journal of Social Studies and Economics, 5(2), 1-22. المصدر : جمعت وحسبت من بيانات الجدول رقم (3) بـ بالملحق .

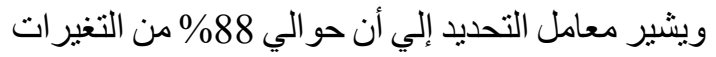

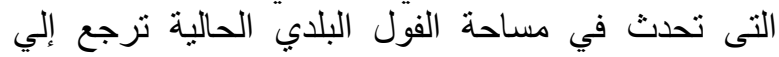

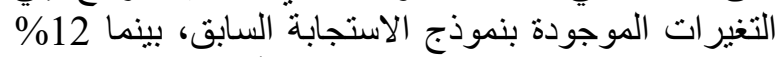

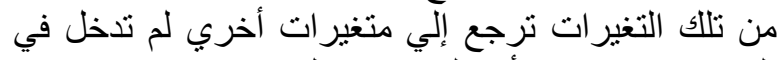
النموذج، في حين أن النموذج النير ككل معنوي أنري عند مستوي

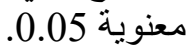

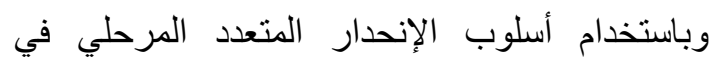

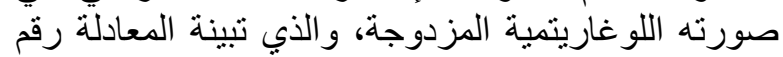

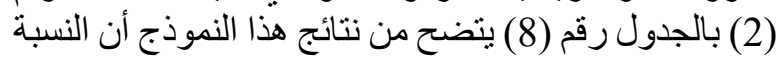

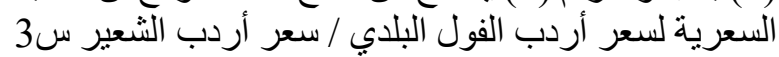

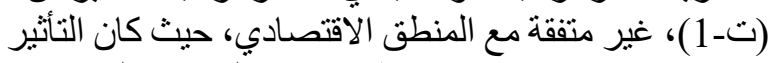

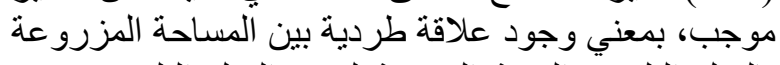

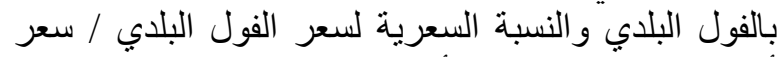

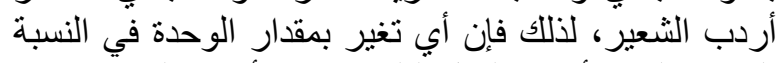

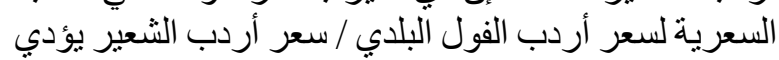

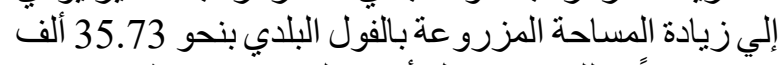
فدان سنوياً وذلك بعد تعديل أرقام النموذج البّان عن طريق إيجاد معكوس اللو غارينت.

كما اتضح من نتائج هذا النموذج أن النسبة السعرية النعارية

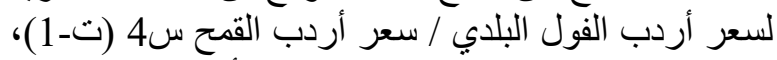

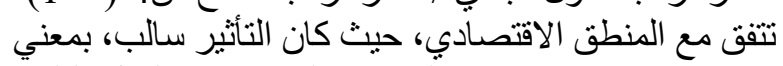

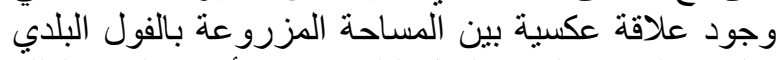

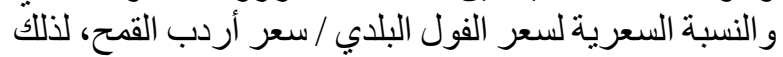

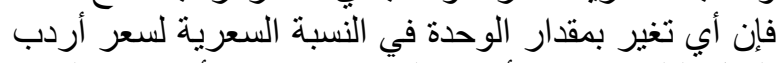

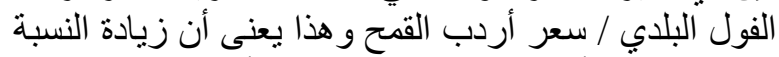
السعرية لسعر أردب الفول الفودي البلدي / سعر أردب الفي القمح بمقدار

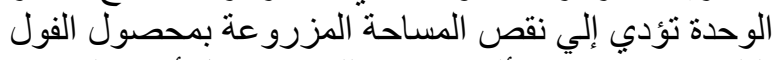

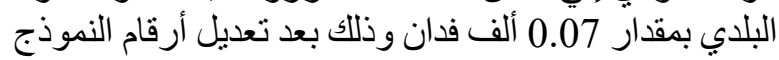
عن طريق إيجاد معكوس اللو غارينت.

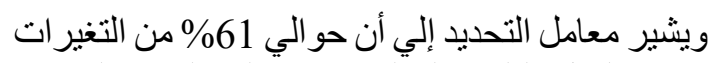

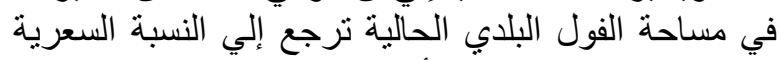

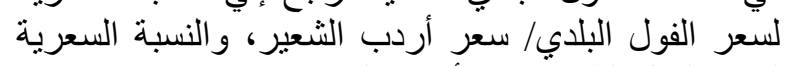

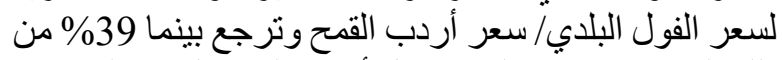

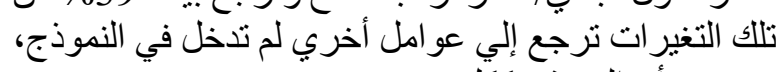

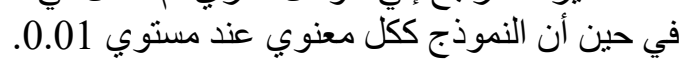

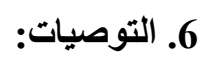
1- العمل علي زيادة المساحة المزرو عة من الفول البلادي البلدي عن طريق التوسع أفقياً في الأر اضي الجديدة. 


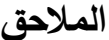

جدول (1) المتغيرات الاقتصادية المؤثرة في استجابة عرض المساحة المزروعة من محصول الفول البلاي في مصر في الصورة المطلقة و المتعلقة بمحصول فئجاية الفول البلاي خلال الفترة (2003- (2019)

\begin{tabular}{|c|c|c|c|c|c|c|}
\hline 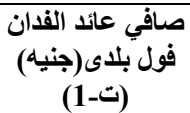 & بلاى (جنيه)(تلفان فول) & سعر الفول البلايه)(ت-1) & 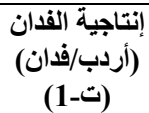 & فساحة الفول (ألف & مساحة الفول البلاى تدان) & السنة \\
\hline 493 & 1367 & 197 & 8.54 & 302.85 & 252.56 & 2003 \\
\hline 573 & 1476 & 218 & 8.60 & 252.56 & 240.85 & 2004 \\
\hline 1306 & 1763 & 326 & 8.85 & 240.85 & 198.17 & 2005 \\
\hline 1310 & 1938 & 331 & 9.17 & 198.17 & 175.35 & 2006 \\
\hline 1381 & 2017 & 347 & 9.11 & 175.35 & 211.97 & 2007 \\
\hline 1215 & 2291 & 353 & 9.18 & 211.97 & 170.11 & 2008 \\
\hline 2376 & 3290 & 581 & 9.26 & 170.11 & 206.00 & 2009 \\
\hline 2179 & 3522 & 573 & 9.24 & 206.00 & 183.69 & 2010 \\
\hline 1565 & 3568 & 575 & 8.15 & 183.69 & 131.43 & 2011 \\
\hline 1474 & 4093 & 596 & 8.54 & 131.43 & 97.906 & 2012 \\
\hline 2605 & 4502 & 717 & 9.18 & 97.906 & 104.92 & 2013 \\
\hline 2543 & 4743 & 730 & 9.58 & 104.92 & 89.707 & 2014 \\
\hline 2529 & 4830 & 740 & 9.48 & 89.707 & 81.934 & 2015 \\
\hline 2524 & 5183 & 805 & 9.35 & 81.934 & 83.356 & 2016 \\
\hline 853 & 6782 & 817 & 9.19 & 83.356 & 121.04 & 2017 \\
\hline 3597 & 8351 & 1286 & 9.07 & 121.04 & 82.181 & 2018 \\
\hline 6984 & 9478 & 1787 & 9.10 & 82.181 & 69.814 & 2019 \\
\hline
\end{tabular}

المصدر : جمعت وحسبت من وزارة الزر اعة و إستصلاح الأر اضي، قطاع الثؤن الاقتصادية، نشرة الإحصاءات الزر اعية ، أعداد متفرقة.

جدول (2) أسعار أهم المحاصيل المؤثرة في استجابة عرض المساحة المزروعة من أهم المحاصيل البقولية في مصر

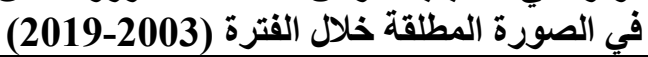

\begin{tabular}{|c|c|c|c|c|c|c|c|c|c|c|}
\hline 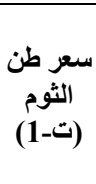 & الثعر طن & أربّ & أردب أحمص & سعر طن & البعر حشّة & سعرأردب & سعرأردب & سعر أردب & 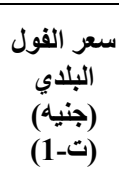 & السنة \\
\hline 650.4 & 228.4 & 172.4 & 351 & 110 & 904 & 108 & 86 & 301 & 197 & 2003 \\
\hline 488 & 230 & 178 & 358 & 110 & 984 & 114 & 90 & 340 & 218 & 2004 \\
\hline 506 & 315 & 350.6 & 371 & 158 & 1026 & 150 & 104 & 451 & 326 & 2005 \\
\hline 655 & 296 & 437 & 383 & 160 & 1148 & 168 & 111 & 472 & 331 & 2006 \\
\hline 1031 & 480 & 467 & 434 & 171 & 1209 & 169 & 123 & 507 & 347 & 2007 \\
\hline 1068 & 603 & 480 & 454 & 187.50 & 1227 & 173 & 149 & 520 & 353 & 2008 \\
\hline 1109 & 659 & 623 & 560 & 231.00 & 1819 & 383 & 254 & 1003 & 581 & 2009 \\
\hline 1316 & 707 & 662 & 543 & 317.22 & 2074 & 242 & 281 & 1023 & 573 & 2010 \\
\hline 2789 & 755 & 674 & 561 & 263.00 & 2176 & 272 & 297 & 1033 & 575 & 2011 \\
\hline 2210 & 840 & 758 & 615 & 355.00 & 3006 & 352 & 304 & 1203 & 596 & 2012 \\
\hline 1452 & 858 & 801 & 822 & 363.50 & 3570 & 378 & 395 & 1220 & 717 & 2013 \\
\hline 1515 & 876 & 838 & 838 & 386.70 & 3655 & 387 & 415 & 1229 & 730 & 2014 \\
\hline 1709 & 959 & 848 & 841 & 370.07 & 3716 & 411 & 432 & 1234 & 740 & 2015 \\
\hline 1779 & 1041 & 870 & 949 & 378.52 & 3866 & 413 & 483 & 1254 & 805 & 2016 \\
\hline 2785 & 1052 & 878 & 960 & 379.37 & 3971 & 416 & 492 & 1274 & 817 & 2017 \\
\hline 2882 & 1525 & 1087 & 2172 & 489.69 & 4629 & 490 & 631 & 2016 & 1286 & 2018 \\
\hline 2979 & 1998 & 1296 & 3384 & 600 & 5288 & 564 & 771 & 2759 & 1787 & 2019 \\
\hline
\end{tabular}

المصدر : جمعت وحسبت من وزارة الزر اعة وإستصلاح الأر اضي، قطاع الثؤن الاقتصادية، نشرة الإحصاءات الزر اعية ، أعداد متفرقة. 


\begin{tabular}{|c|c|c|c|c|c|c|c|c|c|}
\hline سعر الفول / البلدى طن & سعر الفول البلد / البصل & سعر البلأى / الفول & سعر الفول & سعر الفول / البلدى / سن & سعر البلاى / الفول & / سعر الفول البلدى & سعر الفول / الثلأردبر / سعبر & البلأى / الفول & السنة \\
\hline 0.30 & 0.86 & 1.14 & 0.56 & 1.79 & 0.22 & 1.82 & 2.29 & 0.65 & 2003 \\
\hline 0.45 & 0.95 & 1.22 & 0.61 & 1.98 & 0.22 & 1.91 & 2.42 & 0.64 & 2004 \\
\hline 0.64 & 1.03 & 0.93 & 0.88 & 2.06 & 0.32 & 2.17 & 3.13 & 0.72 & 2005 \\
\hline 0.51 & 1.12 & 0.76 & 0.86 & 2.07 & 0.29 & 1.97 & 2.98 & 0.70 & 2006 \\
\hline 0.34 & 0.72 & 0.74 & 0.80 & 2.03 & 0.29 & 2.05 & 2.82 & 0.68 & 2007 \\
\hline 0.33 & 0.59 & 0.74 & 0.78 & 1.88 & 0.29 & 2.04 & 2.37 & 0.67 & 2008 \\
\hline 0.52 & 0.88 & 0.93 & 1.04 & 2.52 & 0.32 & 1.52 & 2.29 & 0.58 & 2009 \\
\hline 0.44 & 0.81 & 0.87 & 1.06 & 1.81 & 0.28 & 2.37 & 2.04 & 0.56 & 2010 \\
\hline 0.21 & 0.76 & 0.85 & 1.02 & 2.19 & 0.26 & 2.11 & 1.94 & 0.55 & 2011 \\
\hline 0.27 & 0.71 & 0.79 & 0.97 & 1.68 & 0.20 & 1.69 & 1.96 & 0.50 & 2012 \\
\hline 0.49 & 0.84 & 0.90 & 0.87 & 1.97 & 0.20 & 1.90 & 1.82 & 0.59 & 2013 \\
\hline 0.48 & 0.83 & 0.87 & 0.87 & 1.89 & 0.20 & 1.89 & 1.76 & 0.59 & 2014 \\
\hline 0.43 & 0.77 & 0.87 & 0.88 & 2.00 & 0.20 & 1.80 & 1.71 & 0.60 & 2015 \\
\hline 0.45 & 0.77 & 0.93 & 0.85 & 2.13 & 0.21 & 1.95 & 1.67 & 0.64 & 2016 \\
\hline 0.29 & 0.78 & 0.93 & 0.85 & 2.15 & 0.21 & 1.96 & 1.66 & 0.64 & 2017 \\
\hline 0.45 & 0.84 & 1.18 & 0.59 & 2.63 & 0.28 & 2.62 & 2.03 & 0.63 & 2018 \\
\hline 0.60 & 0.89 & 1.38 & 0.53 & 2.98 & 0.34 & 3.17 & 2.32 & 0.65 & 2019 \\
\hline
\end{tabular}

المصدر : جمعت وحسبت من بيانات الجدول رقم (2) بالملحق. 